\title{
On-Axis Brilliance and Power of In-Vacuum Undulators for the Advanced Photon Source
}

(formerly MD-TN-2009-004)

\section{R. Dejus, M. Jaski, and S.H. Kim - MD Group/ASD}

Rev. 1, November 25, 2009: Updated the fitted $B_{\text {eff }}$ in Tables $1-3$, and 5 to use two decimals in the fitted equation. Explained chosen gaps. Added clarifications in the text and added additional references. Edited by C. Eyberger for release as cleared document ANL/APS/LS-314; updated in ICMS.

Rev. 0a, June 17, 2009: ICMS Initial Release (minor clarifications and corrections of typographical errors, added footnote "d" to Table 4). Rev. 0, June 16, 2009: First Release as Technical Note MD-TN-2009-004.

\section{Table of Contents}

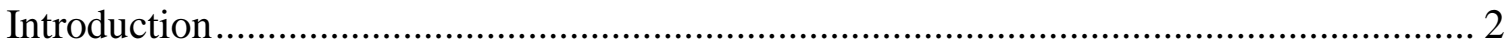

Calculation of the Undulator Effective Magnetic Field................................................ 4

Magnet Modeling............................................................................................. 4

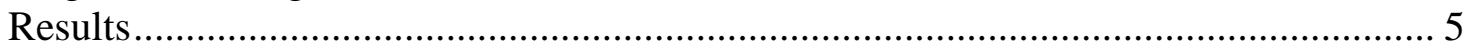

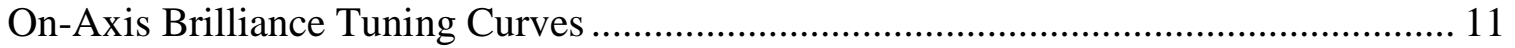

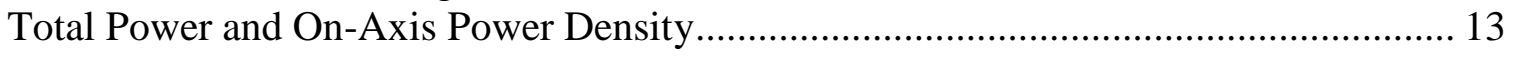

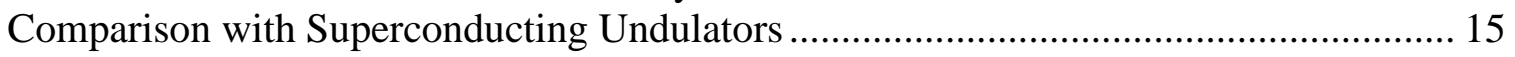

On-Axis Brilliance Tuning Curves for Superconducting Undulators......................... 20

Total Power and On-Axis Power Density for Superconducting Undulators ................ 22

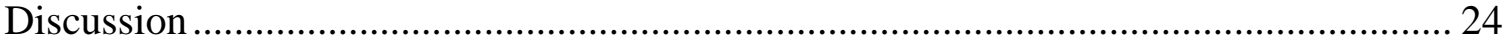

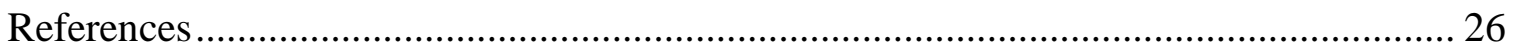




\section{Introduction}

A request for studying the spectral performance of in-vacuum undulators (IVUs) for the APS storage ring was recently put forward. In-vacuum undulators are prevalent at other synchrotron radiation facilities such as the ESRF and the SPring-8. ${ }^{1,2}$ However, they never made it into the arsenal of undulators at the APS because the brilliance tuning curves were sufficiently wide due to the fact that the undulator minimum gap could be set as low as $10.5 \mathrm{~mm}$.

For sector 3, which in the past used a narrow-gap vacuum chamber, the minimum undulator pole gap was allowed to be set as low as $8.5 \mathrm{~mm}$, providing contiguous tuning curves between the first and third harmonic radiation for a 2.7-cm-period device. (Subsequently, the narrow-gap vacuum chamber was removed and replaced with a standard vacuum chamber, which allows a minimum gap of $10.5 \mathrm{~mm}$.) For sector 4, which currently holds the only narrow-gap vacuum chamber at the APS, the minimum gap is $9.5 \mathrm{~mm}$. In this sector, a permanent magnet hybrid undulator with SmCo magnets is used instead of $\mathrm{NdFeB}$ magnets because of their higher radiation resistance and their better protection against radiation-induced demagnetization of the magnets.

In the realm of looking to the future, new concepts and technologies are being revisited. Most notabe is the superconducting undulator (SCU) technology, which provides the ultimate highest magnetic field of any technology and design. The SCU program has been ongoing at the APS for several years and substantial progress has been made. ${ }^{3,4}$ However, the in-vacuum undulators may bridge some of the user demands, and it is therefore worthwhile revisiting their potential at the APS.

In this work, the following were assumed or required:

1) the smallest in-vacuum beam-stay-clear gap is $5.0 \mathrm{~mm}$,

2) a beam-liner of $2 \times 0.060 \mathrm{~mm}$, which increases the pole gap by the same amount, ${ }^{5}$

3) both $\mathrm{NdFeB}$ and SmCo magnets shall be studied, even though SmCo magnets are the preferred choice for very small gaps,

4) compare the in-vacuum undulators with superconducting NbTi undulators with a wall thickness/space of $2 \times 1.0 \mathrm{~mm}$, and

5) all undulators will have an effective magnetic length of $2.4 \mathrm{~m}$.

Three short undulator period lengths were chosen somewhat arbitrary and studied. We will compare the performance of undulators with period lengths of $2.5 \mathrm{~cm}$ and $2.0 \mathrm{~cm}$ to one with a 1.6-cm period, which is the chosen period length of the first designed and tested short-length SCU for the APS. Additionally, we will make comparisons with the undulator A, which has a period length of $3.3 \mathrm{~cm}$. 
All results were obtained for the following beam conditions:

- the APS beam energy is $7.0 \mathrm{GeV}$ and the beam current is $100 \mathrm{~mA}$, and

- the APS beam parameters for the $2.5 \mathrm{~nm}$-rad, low-emittance lattice in topup operation were used:

$$
\begin{aligned}
& \text { o } \sigma_{x}=0.275 \mathrm{~mm}, \\
& \text { o } \sigma_{y}=0.009 \mathrm{~mm}, \\
& \text { o } \sigma_{x}=0.0113 \mathrm{mrad}, \\
& \text { o } \sigma_{y}=0.0030 \mathrm{mrad} \text {, and } \\
& \text { o a beam energy spread of } 9.6 \times 10^{-4} .
\end{aligned}
$$




\section{Calculation of the Undulator Effective Magnetic Field}

\section{Magnet Modeling}

There are several ways to estimate the undulator effective magnetic field $B_{\text {eff }}$ at small gaps for a real device. Instead of extrapolating from empirical data of the existing undulators at the APS, which were typically measured at a minimum gap of $10.5 \mathrm{~mm}$ for undulators made of $\mathrm{NdFeB}$ (with the exception of one undulator made of SmCo), we have performed design optimization of the actual geometry for several periods and gaps covering gap-to-period ratios in the range $0.1-0.6$. Two-dimensional (2D) modeling was performed for a planar hybrid undulator for both SmCo and NdFeB magnets with vanadium permendur poles. Three-dimensional (3D) modeling demands substantially more computer time and was deemed unnecessary for this work (see Discussion section for more information). Magnets made of SmCo are preferred for IVUs at small undulator gaps because of their higher radiation resistance, thus reducing the potential issue of radiation-induced demagnetization of the magnets.

Figure 1 shows the general layout of the geometry used in the 2D optimization model. The OPERA 2-D Optimizer from Cobham Technical Services ${ }^{6}$ was used for each period and gap. The design variables were the permanent magnet (PM) width (and hence the pole width), the PM chamfer-z, the PM chamfer-y, the pole chamfer- $z$, and the pole chamfer-y. These were optimized to obtain the maximum effective magnetic field in the undulator midplane. The PM height and the pole height were scaled from the period ratio from a known optimized 27-mm-period model with PM height and pole height equal to $54.4 \mathrm{~mm}$ and $45.24 \mathrm{~mm}$, respectively.
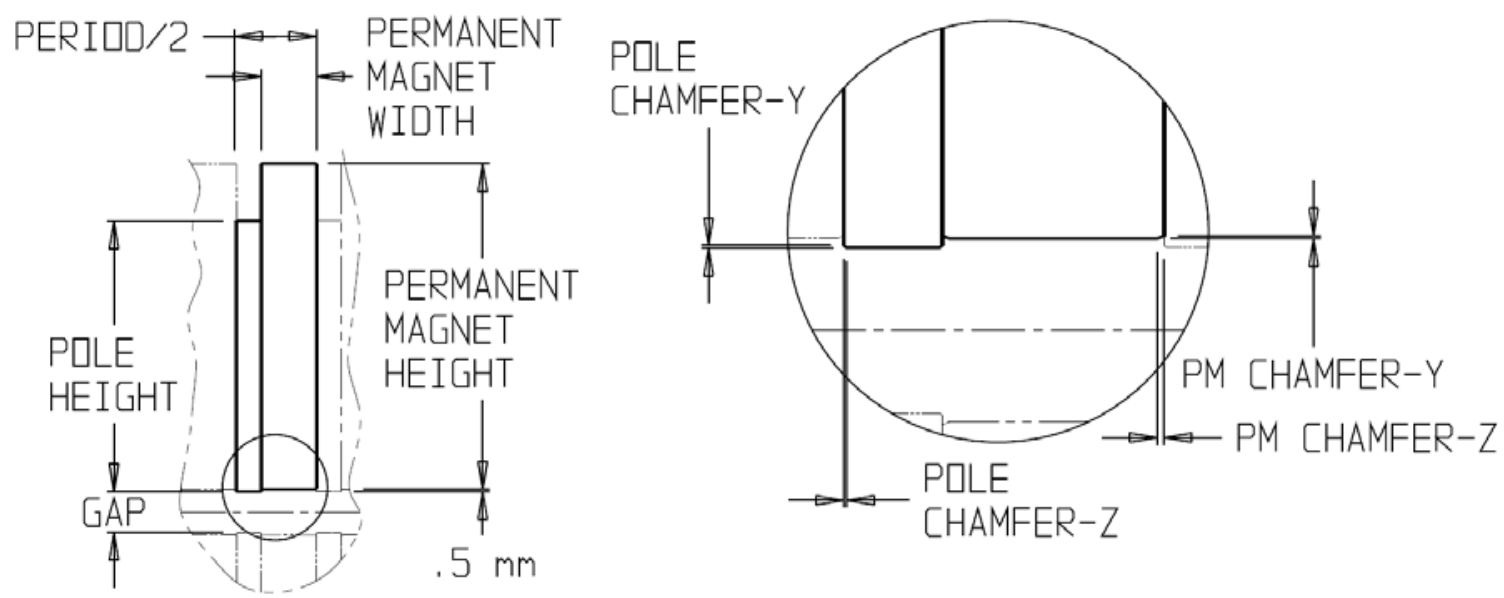

Fig. 1. General layout of the magnets and poles used in the two-dimensional optimization model. The right view shows a close-up of the chamfers near the beam axis. In $2 \mathrm{D}$, the transverse widths of the magnets and poles may be considered infinite. 


\section{Results}

Figure 2 shows the $B_{\text {eff }}$ values for IVUs made of SmCo magnets and vanadium permendur poles for undulator gaps ranging from $5.12 \mathrm{~mm}$ to $8.87 \mathrm{~mm}$. A beam-liner of $0.12 \mathrm{~mm}$ was added to all beam-stay-clear dimensions. The beam-stay-clear gap of 8.75 mm was chosen because it provides the same impedance as that of the APS standard undulator vacuum chamber, which allows a 10.5 -mm undulator gap settting. ${ }^{7,8}$ If $B_{\text {eff }}$ is plotted versus the undulator-gap-to-period ratio $(r)$, it follows closely a second-order exponential curve. (The effective magnetic field determines the radiated harmonic energies, and it is the value of importance here.)

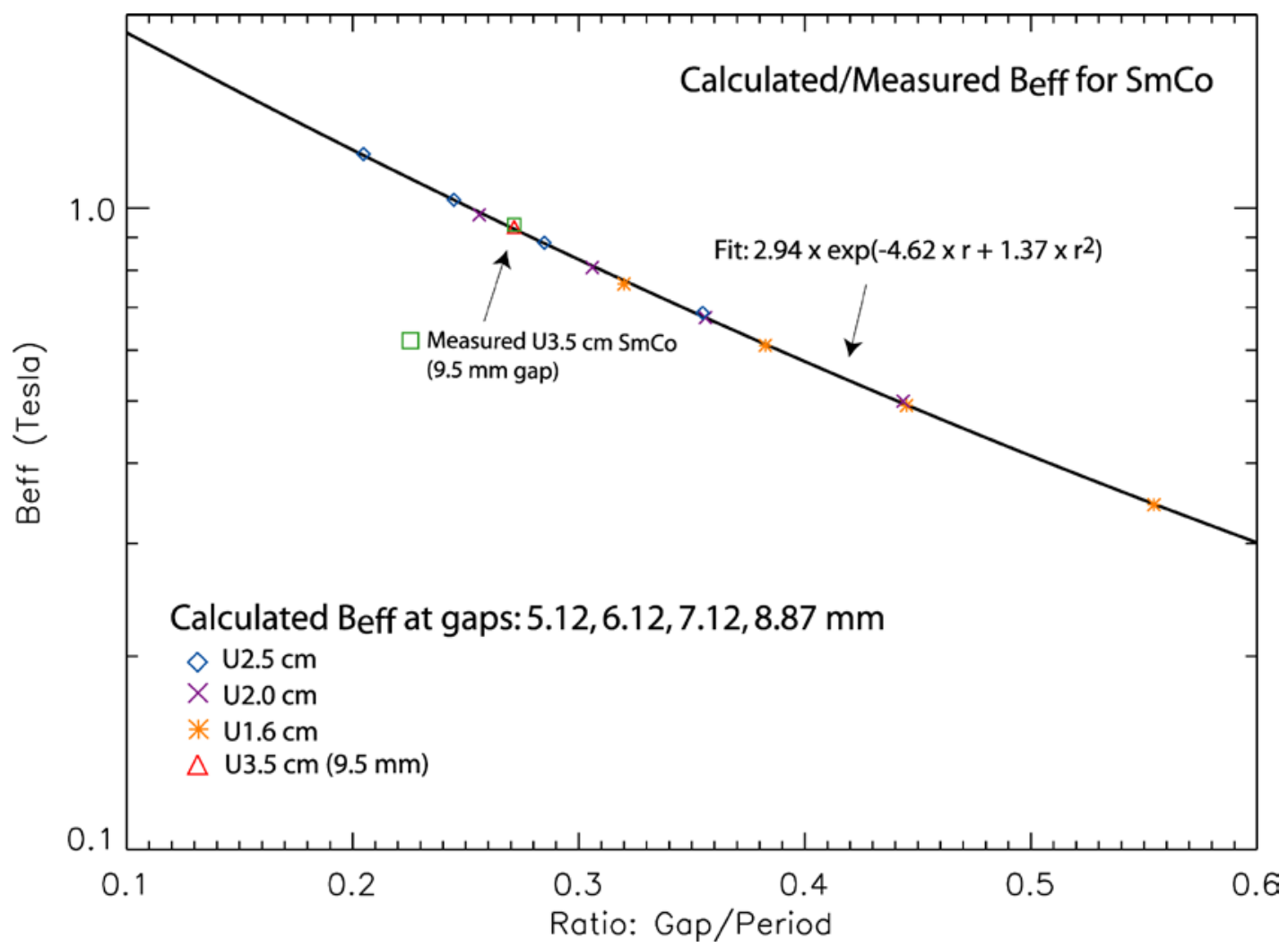

Fig. 2. Calculated and fitted effective $B$ values $\left(B_{\text {eff }}\right)$ versus the ratio of the undulator-gap-toperiod length $(r$ ) for planar permanent magnet hybrid undulators made with SmCo magnets and vanadium permendur poles. The solid black curve shows a second-order exponential fitted to the calculated 13 data points in the $r$ range from 0.20 to 0.55 . The fit is better than $\pm 1.3 \%$ for all data points, and the rms value of the deviations is $0.71 \%$. The green square shows the measured effective magnetic field of the U3.5-cm undulator at 9.5-mm gap. The measured $B_{\text {eff }}$ is $0.8 \%$ higher than what the model predicts. The remanence magnetic field $B_{r}$ of 1.12 Tesla and the coercivity $H_{c B}$ of 9800 Oersteds were used in the model calculations (grade R32HS from ShinEtsu). 
Figure 3 shows the corresponding results for $\mathrm{NdFeB}$ magnet designs using gaps of $8.50 \mathrm{~mm}$ and $10.5 \mathrm{~mm}$ for out-of-vacuum positions. The $B_{\text {eff }}$ calculated from the Halbach expression is also shown in the figure. ${ }^{9}$

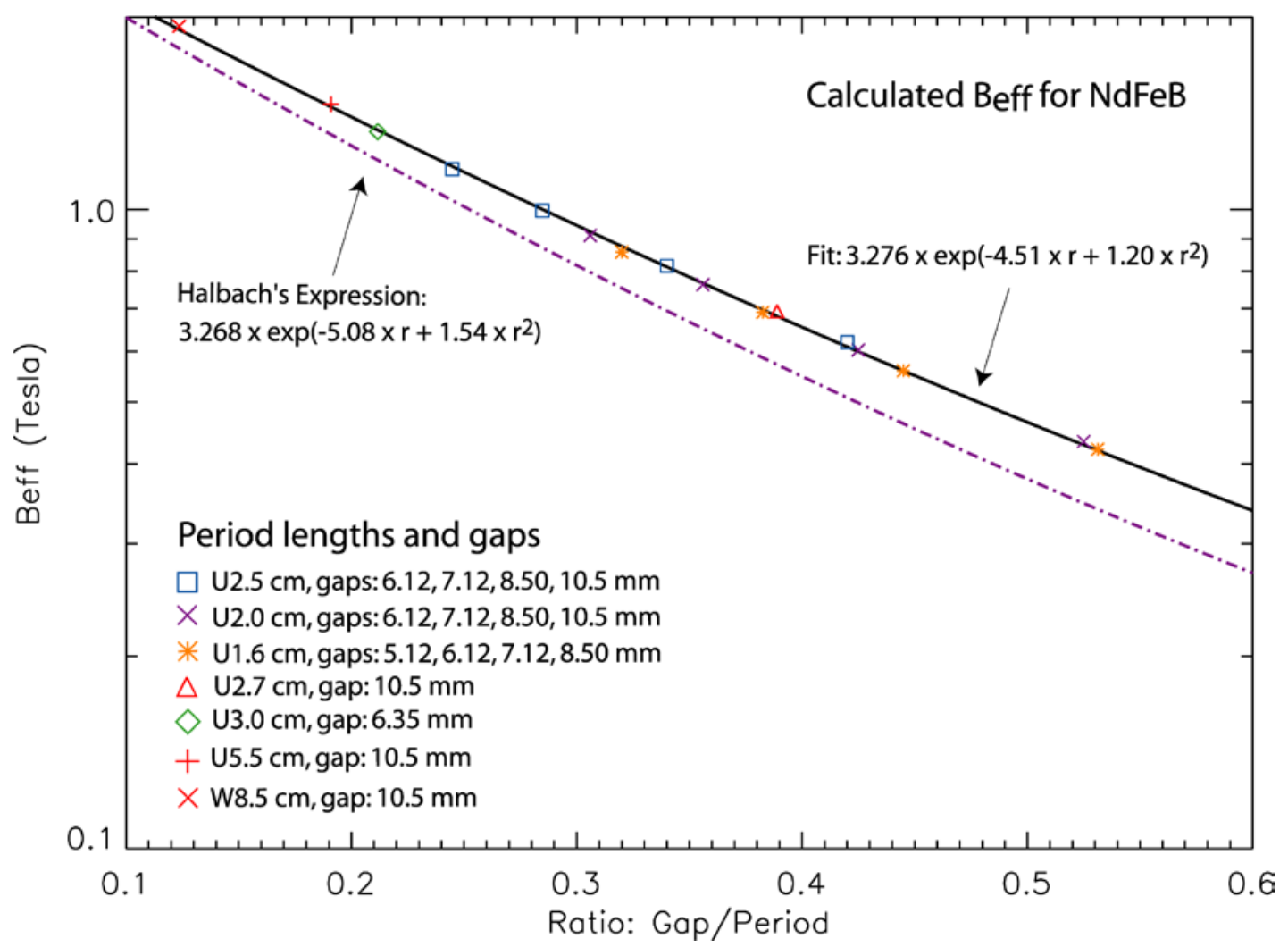

Fig. 3. Calculated and fitted effective $B$ values $\left(B_{\text {eff }}\right)$ versus the ratio of the undulator-gap-toperiod length $(r$ ) for planar permanent magnet hybrid undulators made with $\mathrm{NdFeB}$ magnets and vanadium permendur poles. The solid black curve shows a second-order exponential fitted to the calculated 17 data points in the $r$ range from 0.12 to 0.66 . (The data point for $r=0.66$, which corresponds to a gap of $10.5 \mathrm{~mm}$ and a period length of $16.0 \mathrm{~mm}$ is not shown.) The fit is better than $\pm 2.1 \%$ for all data points, and the rms value of the deviations is $1.1 \%$. The remanence magnetic field $B_{r}$ of 1.22 Tesla and the coercivity $H_{c B}$ of 11500 Oersteds were used in the model calculations (grade N39UH from Shin-Etsu). The Halbach expression is shown by the dasheddotted curve. 
A comparison of the calculated $B_{\text {eff }}$ to measured values of existing undulators at the APS is shown in Fig. 4. It is apparent that the 2D model provides reasonably good agreement in most cases.

The tabulated results of the magnet modeling calculations are shown in Tables 1 and 2, and for comparison, the measured magnetic fields of the currently installed undulators at the APS are summarized in Table 3.

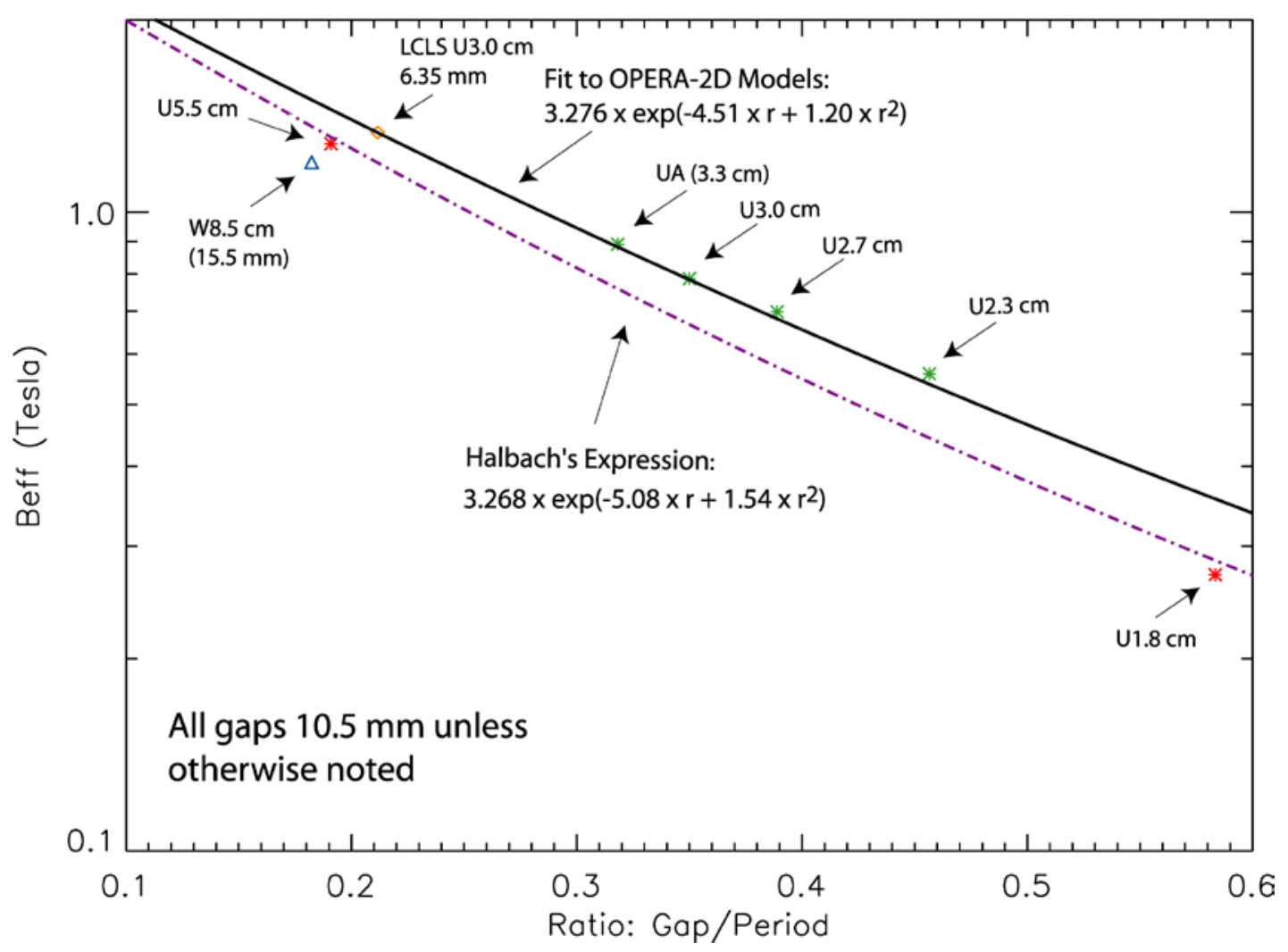

Fig. 4. Comparison of fit to computed effective $B$ values $\left(B_{\text {eff }}\right)$ and measured values versus the ratio of the undulator-gap-to-period length $(r)$ for planar permanent magnet hybrid undulators made with NdFeB magnets and vanadium permendur poles. The model fit and the Halbach expression are the same as in Fig. 3. The measured values are listed in Table 3. The magnet grades of the measured undulators are not all the same and are not always the magnet grade N39UH assumed in the model calculations. The fitted values are typically lower than the measurements by a few percent, except for the U1.8-cm and U5.5- $\mathrm{cm}$ undulators, and the W8.5$\mathrm{cm}$ wiggler, which were not optimized and used much weaker magnets than the model assumed. 
Table 1: Calculated and fitted effective magnetic fields and effective $K$ values for SmCo magnet designs for chosen combination of undulator period lengths and pole gaps.

\begin{tabular}{lccccccc}
\hline $\begin{array}{l}\text { Undulator Period } \\
\text { and Type }^{\mathrm{a}}\end{array}$ & $\begin{array}{c}\text { Pole } \\
\text { Gap } \\
(\mathrm{mm})\end{array}$ & $\begin{array}{c}\text { Gap-to- } \\
\text { Period } \\
\text { Ratio }\end{array}$ & $\begin{array}{c}B_{\text {eff }}(\text { Tesla) } \\
\text { (Calc./Fit) }\end{array}$ & $K_{\text {eff }}{ }^{\mathrm{c}}$ & $\begin{array}{c}E_{1}{ }^{\mathrm{d}} \\
(\mathrm{keV})\end{array}$ & $\begin{array}{c}P_{\text {density }}{ }^{\mathrm{e}} \\
\left(\mathrm{kW} / \mathrm{mrad}^{2}\right)\end{array}$ & $\begin{array}{c}P_{\text {total }}{ }^{\mathrm{e}} \\
(\mathrm{kW})\end{array}$ \\
\hline \multirow{3}{*}{$\mathrm{U} 2.5 \mathrm{~cm}$} & & & & & & & \\
& 5.12 & 0.205 & $1.2143 / 1.2089$ & 2.835 & 3.71 & 300.6 & 11.0 \\
& 6.12 & 0.245 & $1.0304 / 1.0300$ & 2.405 & 4.78 & 254.0 & 7.9 \\
& 7.12 & 0.285 & $0.8831 / 0.8814$ & 2.061 & 5.96 & 216.7 & 5.8 \\
$\mathrm{U} 2.0 \mathrm{~cm}$ & 8.87 & 0.355 & $0.6864 / 0.6782$ & 1.602 & 8.15 & 166.9 & 3.5 \\
& & & & & & & \\
& 5.12 & 0.256 & $0.9760 / 0.9856$ & 1.823 & 8.74 & 298.2 & 7.1 \\
& 6.12 & 0.306 & $0.8080 / 0.8130$ & 1.509 & 10.9 & 245.0 & 4.9 \\
$\mathrm{U} 1.6 \mathrm{~cm}$ & 7.12 & 0.356 & $0.6749 / 0.6752$ & 1.260 & 13.0 & 202.7 & 3.4 \\
& 8.87 & 0.444 & $0.5000 / 0.4960$ & 0.934 & 16.2 & 147.0 & 1.9 \\
& & & & & & & \\
& 5.12 & 0.320 & $0.7617 / 0.7713$ & 1.138 & 17.7 & 284.4 & 4.3 \\
& 6.12 & 0.383 & $0.6107 / 0.6137$ & 0.912 & 20.5 & 223.7 & 2.8 \\
$\mathrm{U} 3.5 \mathrm{~cm}^{\mathrm{f}}$ & 7.12 & 0.445 & $0.4923 / 0.4935$ & 0.735 & 22.9 & 174.5 & 1.8 \\
& 8.87 & 0.554 & $0.3447 / 0.3458$ & 0.515 & 25.7 & 109.7 & 0.9 \\
\hline
\end{tabular}

${ }^{a}$ All devices are $2.4 \mathrm{~m}$ long. The magnet modeling code OPERA from Cobham Technical Services was used to optimize the geometry. The remanence magnetic field $B_{r}$ of 1.12 Tesla and the coercivity $H_{c B}$ of 9800 Oersteds were used in the model calculations (grade R32HS from Shin-Etsu).

${ }^{\mathrm{b}}$ The fit to computed values are from the equation $B_{\text {eff, fit }}=2.94 \times \exp \left(-4.62 r+1.37 r^{2}\right)$, where $r=$ gap/period. The same function was plotted in Fig. 2.

${ }^{\mathrm{c}} K_{\text {eff }}$ was calculated from the calculated $B_{\text {eff }}$.

${ }^{\mathrm{d}}$ Zero-emittance calculation using $K_{\text {eff }}$ for on-axis radiation for a beam energy of $7.0 \mathrm{GeV}$.

${ }^{\mathrm{e}}$ Zero-emittance calculation using the effective magnetic field for a beam energy of $7.0 \mathrm{GeV}$ and a beam current of $100 \mathrm{~mA}$.

f The $\mathrm{U} 3.5 \mathrm{~cm}$ was included so that a comparison could be made to the measured $B_{\text {eff }}(0.9417$ Tesla) at 9.50-mm gap. 
Table 2: Calculated and fitted effective magnetic fields and effective $K$ values for NdFeB magnet designs for chosen combination of undulator period lengths and pole gaps.

\begin{tabular}{|c|c|c|c|c|c|c|c|}
\hline $\begin{array}{l}\text { Undulator Period } \\
\text { and Type }^{\text {a }}\end{array}$ & $\begin{array}{c}\text { Pole } \\
\text { Gap } \\
(\mathrm{mm}) \\
\end{array}$ & $\begin{array}{c}\text { Gap-to- } \\
\text { Period } \\
\text { Ratio } \\
\end{array}$ & $\begin{array}{l}B_{\text {eff }} \text { (Tesla) } \\
\text { (Calc./Fit) }^{\mathrm{b}}\end{array}$ & $\overline{K_{e f f}{ }^{c}}$ & $\begin{array}{c}E_{1}{ }^{\mathrm{d}} \\
(\mathrm{keV})\end{array}$ & $\begin{array}{c}P_{\text {density }}{ }^{\mathrm{e}} \\
\left(\mathrm{kW} / \mathrm{mrad}^{2}\right)\end{array}$ & $\begin{array}{c}P_{\text {total }} \\
(\mathrm{kW})\end{array}$ \\
\hline $\mathrm{U} 2.5 \mathrm{~cm}$ & $\begin{array}{c}6.12 \\
7.12 \\
8.50 \\
10.5\end{array}$ & $\begin{array}{l}0.245 \\
0.285 \\
0.340 \\
0.420\end{array}$ & $\begin{array}{l}1.1562 / 1.1671 \\
0.9955 / 0.9995 \\
0.8163 / 0.8122 \\
0.6201 / 0.6090\end{array}$ & $\begin{array}{l}2.699 \\
2.324 \\
1.906 \\
1.448\end{array}$ & $\begin{array}{l}4.01 \\
5.03 \\
6.61 \\
9.09\end{array}$ & $\begin{array}{l}285.8 \\
245.2 \\
199.9 \\
150.2\end{array}$ & $\begin{array}{l}9.9 \\
7.4 \\
5.0 \\
2.9\end{array}$ \\
\hline $\mathrm{U} 2.0 \mathrm{~cm}$ & $\begin{array}{c}6.12 \\
7.12 \\
8.50 \\
10.5\end{array}$ & $\begin{array}{l}0.306 \\
0.356 \\
0.425 \\
0.525\end{array}$ & $\begin{array}{l}0.9106 / 0.9221 \\
0.7630 / 0.7658 \\
0.6029 / 0.5985 \\
0.4334 / 0.4273\end{array}$ & $\begin{array}{l}1.701 \\
1.425 \\
1.126 \\
0.809\end{array}$ & $\begin{array}{l}9.51 \\
11.5 \\
14.2 \\
17.5\end{array}$ & $\begin{array}{l}277.5 \\
230.7 \\
180.0 \\
125.0\end{array}$ & $\begin{array}{l}6.2 \\
4.3 \\
2.7 \\
1.4\end{array}$ \\
\hline $\mathrm{U} 1.6 \mathrm{~cm}$ & $\begin{array}{c}5.12 \\
6.12 \\
7.12 \\
8.50 \\
10.5\end{array}$ & $\begin{array}{l}0.320 \\
0.383 \\
0.445 \\
0.531 \\
0.656\end{array}$ & $\begin{array}{l}0.8581 / 0.8749 \\
0.6905 / 0.6957 \\
0.5593 / 0.5584 \\
0.4214 / 0.4187 \\
0.2819 / 0.2847\end{array}$ & $\begin{array}{l}1.282 \\
1.032 \\
0.836 \\
0.630 \\
0.421\end{array}$ & $\begin{array}{l}16.0 \\
19.0 \\
21.6 \\
24.3 \\
26.7\end{array}$ & $\begin{array}{r}322.6 \\
256.1 \\
202.8 \\
144.1 \\
81.3\end{array}$ & $\begin{array}{l}5.5 \\
3.6 \\
2.3 \\
1.3 \\
0.6\end{array}$ \\
\hline $\mathrm{U} 2.7 \mathrm{~cm}$ & 10.5 & 0.389 & 0.6932/0.6799 & 1.748 & 6.82 & 155.1 & 3.5 \\
\hline $\mathrm{U} 3.0 \mathrm{~cm}^{\mathrm{f}}$ & 6.35 & 0.212 & $1.3241 / 1.3308$ & 3.709 & 1.97 & 274.2 & 13.0 \\
\hline $\mathrm{U} 5.5 \mathrm{~cm}$ & 10.5 & 0.191 & $1.4615 / 1.4468$ & 7.506 & 0.29 & 163.4 & 15.7 \\
\hline W $8.5 \mathrm{~cm}$ & 10.5 & 0.124 & $1.9355 / 1.9114$ & 15.36 & 0.05 & 141.0 & 27.6 \\
\hline
\end{tabular}

${ }^{\mathrm{a}}$ All devices are $2.4 \mathrm{~m}$ long. The magnet modeling code OPERA from Cobham Technical Services was used to optimize the geometry. The remanence magnetic field $B_{r}$ of 1.22 Tesla and the coercivity $H_{c B}$ of 11500 Oersteds were used in the model calculations (grade N39UH from Shin-Etsu).

${ }^{\mathrm{b}}$ The fit to computed values are from the equation $B_{\text {eff } f \text { fit }}=3.276 \times \exp \left(-4.51 r+1.20 r^{2}\right)$, where $r=$ gap/period. The same function was plotted in Fig. 3.

${ }^{\mathrm{c}} K_{\text {eff }}$ was calculated from the calculated $B_{\text {eff }}$.

${ }^{\mathrm{d}}$ Zero-emittance calculation using $K_{\text {eff }}$ for on-axis radiation for a beam energy of $7.0 \mathrm{GeV}$.

${ }^{\mathrm{e}}$ Zero-emittance calculation using the effective magnetic field for a beam energy of $7.0 \mathrm{GeV}$ and a beam current of $100 \mathrm{~mA}$.

f The 3.0-cm period length and gap of $6.35 \mathrm{~mm}$ were chosen to correspond to the parameters for the LCLS undulator. 
Table 3: Measured and fitted effective magnetic fields, derived effective $K$ values, first-harmonic energies, and powers for undulators installed on the APS storage ring. A beam energy of $7.0 \mathrm{GeV}$ and a beam current of $100 \mathrm{~mA}$ were assumed in the calculations of the first- harmonic energies and powers.

\begin{tabular}{|c|c|c|c|c|c|c|c|}
\hline $\begin{array}{l}\text { Undulator Period } \\
\text { and Type }^{\text {a }}\end{array}$ & $\begin{array}{c}\text { Periods } \\
N^{\mathrm{b}}\end{array}$ & $\begin{array}{c}\text { Pole } \\
\text { Gap } \\
(\mathrm{mm})\end{array}$ & $\begin{array}{l}B_{\text {eff }}(\text { Tesla) } \\
\text { (Meas./Fit) }^{c}\end{array}$ & $K_{\text {eff }}{ }^{d}$ & $\begin{array}{c}E_{1}{ }^{\mathrm{e}} \\
(\mathrm{keV})\end{array}$ & $\begin{array}{c}P_{\text {density }}{ }^{\mathrm{f}} \\
\left(\mathrm{kW} / \mathrm{mrad}^{2}\right)\end{array}$ & $\begin{array}{l}P_{\text {total }} \\
(\mathrm{kW})\end{array}$ \\
\hline Wiggler 8.5 cm (1) & 28 & 15.5 & $1.1974 / 1.4980$ & 9.50 & 0.12 & 87.2 & 10.6 \\
\hline $\mathrm{U} 5.5 \mathrm{~cm}(1)^{\mathrm{g}}$ & 43 & 10.5 & $1.2791 / 1.4468$ & 6.57 & 0.37 & 142.9 & 12.0 \\
\hline UA $3.3 \mathrm{~cm}$ (23) & 72 & 10.5 & $0.8906 / 0.8808$ & 2.74 & 2.96 & 168.0 & 6.0 \\
\hline U 3.0 cm (5) & 79 & 10.5 & $0.7867 / 0.7828$ & 2.20 & 4.54 & 159.0 & 4.5 \\
\hline U $2.7 \mathrm{~cm} \mathrm{(3)}$ & 88 & 10.5 & 0.6980/0.6799 & 1.76 & 6.76 & 156.2 & 3.6 \\
\hline U $2.3 \mathrm{~cm} \mathrm{(3)}$ & 103 & 10.5 & $0.5584 / 0.5368$ & 1.20 & 11.8 & 143.7 & 2.3 \\
\hline $\mathrm{U} 1.8 \mathrm{~cm}(1)$ & 198 & 10.5 & $0.2707 / 0.3549$ & 0.45 & 23.5 & 105.7 & 0.8 \\
\hline U 3.5 cm, SmCo (1) & 67 & 9.50 & $0.9417 / 0.9281$ & 3.08 & 2.31 & 163.0 & 6.5 \\
\hline $\mathrm{U} 3.0 \mathrm{~cm}, \operatorname{LCLS}(1)^{\mathrm{h}}$ & 113 & 6.35 & $1.3324 / 1.3308$ & 3.73 & 1.95 & 389.5 & 18.6 \\
\hline
\end{tabular}

${ }^{a}$ The magnet material is NdFeB unless otherwise noted. The undulator period length is given in the device name. Not all magnet grades were the same for any given period length. The values in parentheses indicate the number of undulators of each period length that were used in the calculation of the average effective magnetic field $B_{\text {eff. }}$

${ }^{\mathrm{b}}$ All devices are $2.4 \mathrm{~m}$ long. The number of periods includes the non-full-strength end poles.

${ }^{\mathrm{C}}$ The fit to computed values are from $B_{\text {eff }, \text { fit }}=3.276 \times \exp \left(-4.51 r+1.20 r^{2}\right)$, where $r=$ gap/period. The same function was plotted in Fig. 3.

${ }^{\mathrm{d}} K_{\text {eff }}$ was calculated from the measured $B_{\text {eff }}$.

${ }^{\mathrm{e}}$ Zero-emittance calculation using $K_{\text {eff }}$ for on-axis radiation for a beam energy of $7.0 \mathrm{GeV}$.

${ }^{\mathrm{f}}$ Zero-emittance calculation using the effective magnetic field $B_{\text {eff }}$, except for undulator A, which used the peak magnetic field $B_{\text {peak }}(0.9056$ Tesla), for a beam energy of $7.0 \mathrm{GeV}$ and a beam current of $100 \mathrm{~mA}$. For the superconducting undulator (SCU $1.6 \mathrm{~cm}$ ), which is assumed to provide 0.784 Tesla at a pole gap of 9.0 $\mathrm{mm}$, the first-harmonic energy occurs at $17.2 \mathrm{keV}$ and the total power and on-axis power density is $4.6 \mathrm{~kW}$ and $293.2 \mathrm{~kW} / \mathrm{mrad}^{2}$, respectively for $N=150(2.4 \mathrm{~m})$. The total power and the on-axis power density scale linearly with the device length $L$. The total power is proportional to the square of the magnetic field.

$\mathrm{g}$ The U 5.5-cm-period undulator as installed on the APS storage ring is not allowed to close to $10.5 \mathrm{~mm}$ gap due to excessive total power emitted. The current minimum gap is $14.0 \mathrm{~mm}$, which corresponds to a total power of $6.9 \mathrm{~kW}$ and a power density of $108.0 \mathrm{~kW} / \mathrm{mrad}^{2}$.

h The LCLS prototype undulator (3.0-cm period), which was thoroughly characterized at the APS, is included for reference only. It was never installed on the APS storage ring. 


\section{On-Axis Brilliance Tuning Curves}

It is important to realize that for any given undulator period and undulator length, the tuning curves will look the same; it is only the lowest reachable energy that varies, which in turn depends on the maximum achievable magnetic field. This is illustrated in Fig. 5, which shows tuning curves of the first three odd harmonics for a 2.5-cm-period undulator assuming ideal magnetic fields. (Real-field devices would show somewhat reduced brilliance of the higher harmonics, which is not important here.) Markers indicate the lowest reachable harmonic energies of the SmCo and the NbFeB magnets. The beginning of each harmonic tuning curve corresponds to a beam stay-clear minimum gap of $5.0 \mathrm{~mm}$ for the SmCo magnet undulators.

The higher the maximum magnetic field (the smaller the minimum gap), the wider the tuning range of the different harmonics, hence the wider coverage for the stronger NdFeB magnets. As is seen in Fig. 5, the first- and third-harmonic tuning curves close near a gap of $6.0 \mathrm{~mm}$ for SmCo magnets and $7.0 \mathrm{~mm}$ for NdFeB magnets for this period length.

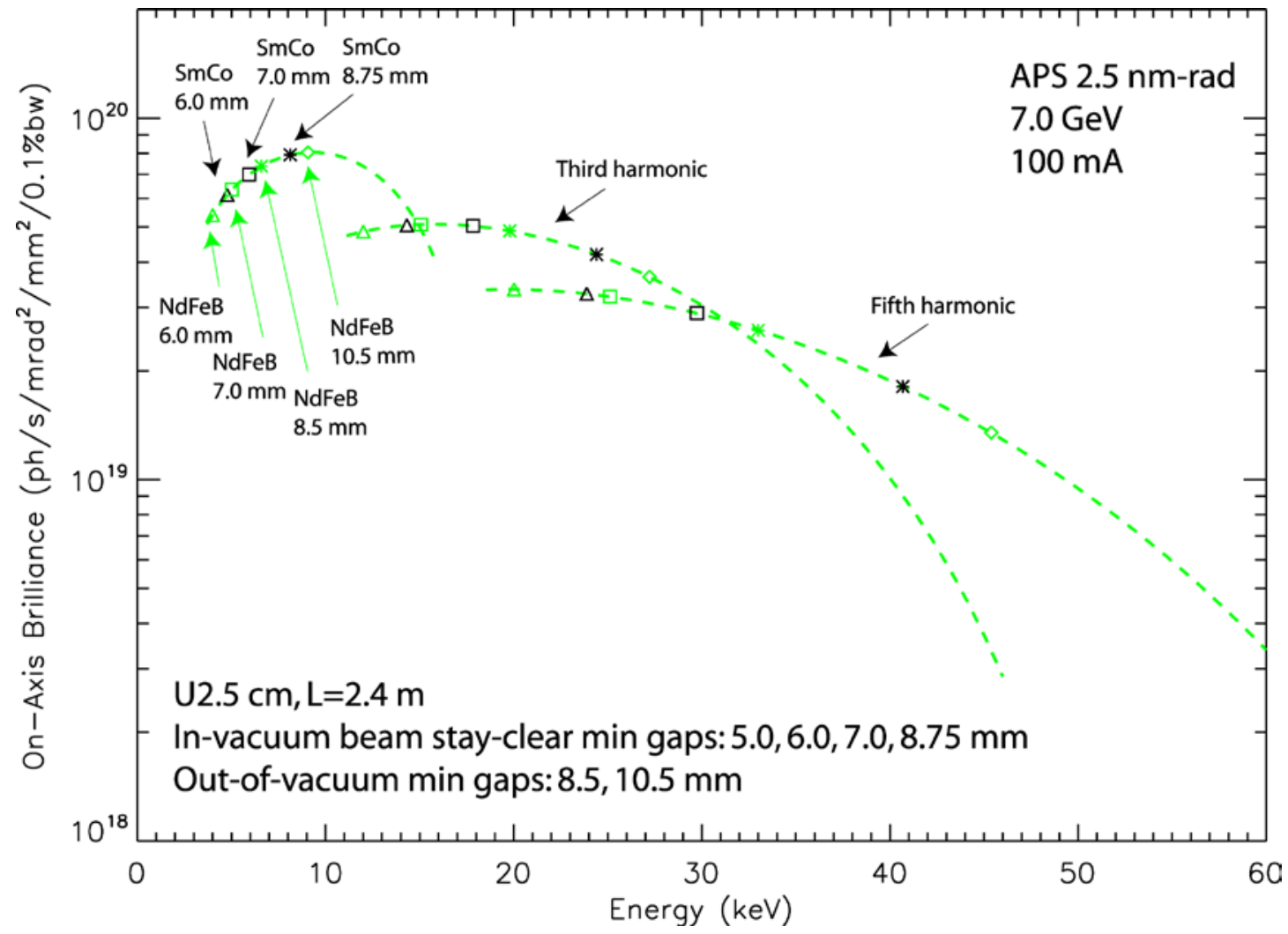

Fig. 5. On-axis brilliance tuning curves for a 2.4-m-long, 2.5-cm-period undulator (U2.5 cm) for harmonics 1,3 , and 5 in linear horizontal polarization mode for $7.0-\mathrm{GeV}$ beam energy and 100$\mathrm{mA}$ beam current. Six different gaps and two different magnet materials were studied. The minimum reachable harmonic energies were calculated assuming SmCo magnets and a 5.0-mm beam stay-clear gap. The smallest gap for the NdFeB magnets is $6.0 \mathrm{~mm}$. The first- and thirdharmonic tuning curves close near a gap of $6.0 \mathrm{~mm}$ for the SmCo magnets and $7.0 \mathrm{~mm}$ for the $\mathrm{NdFeB}$ magnets. Ideal magnetic fields were assumed. 
For the in-vacuum undulator gaps, the actual gaps were $0.12 \mathrm{~mm}$ larger than those listed in the figure. The "extra" 0.12-mm space would be taken up by a Cu-Ni sheet covering the magnets and poles to minimize the beam impedence of the undulator vacuum chamber. (For the out-of-vacuum gaps listed, the gaps are the actual pole-to-pole gaps, and the beam-stay-clear is 2.0 to $2.5 \mathrm{~mm}$ smaller due to a predetermined pole-tovacuum-chamber clearance and the wall thickness of the vacuum chamber.)

The calculated on-axis brilliance tuning curves for three in-vacuum undulators with period lengths ranging from $1.6 \mathrm{~cm}$ to $2.5 \mathrm{~cm}$ are shown in Fig. 6. (The tuning curves for the U2.5-cm undulator are the same as in Fig. 5.)

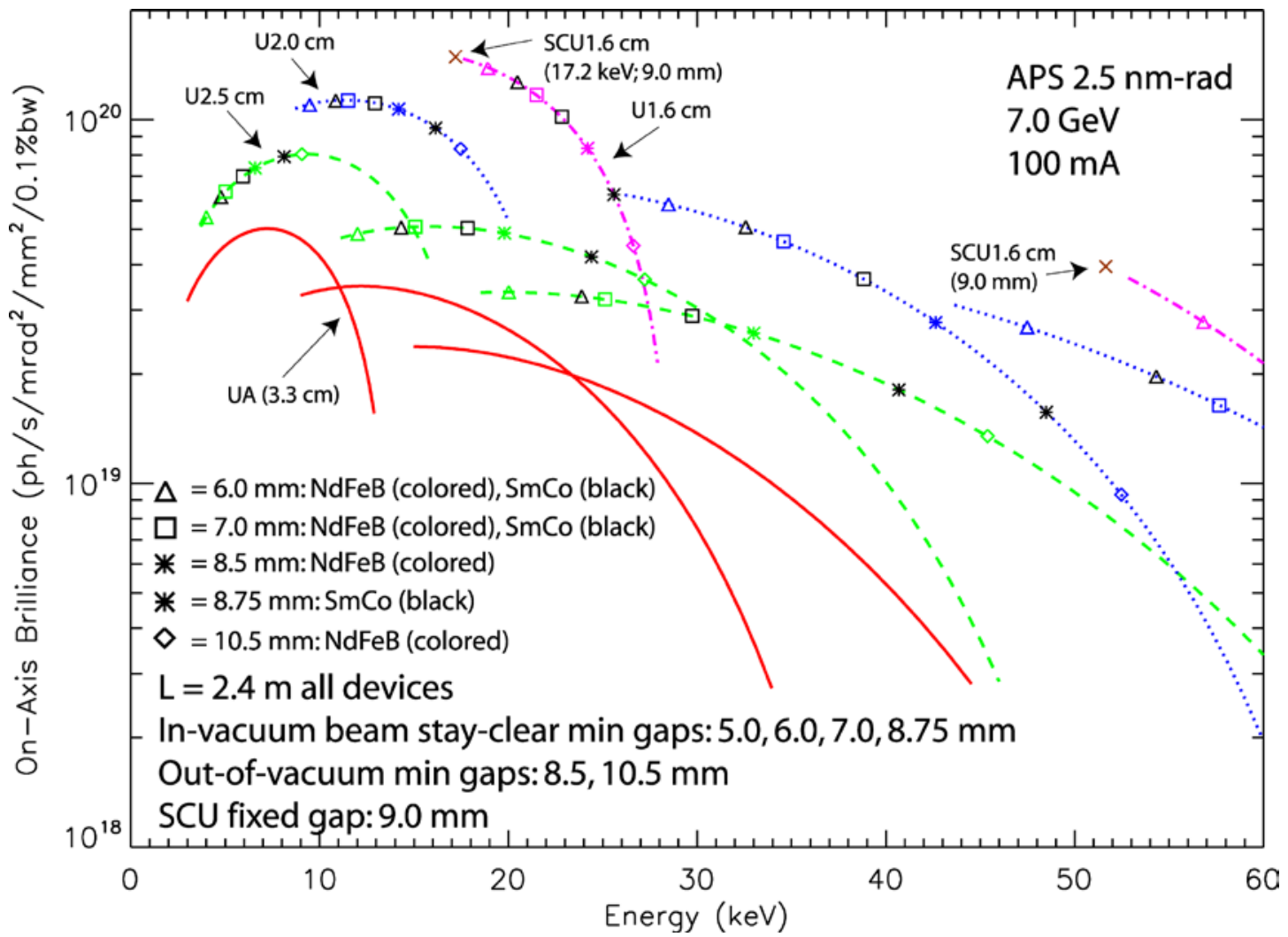

Fig. 6. On-axis brilliance tuning curves for three in-vacuum undulators (1.6-cm, 2.0-cm, and 2.5cm periods, each $2.4 \mathrm{~m}$ long) compared to undulator A for harmonics 1 , 3 , and 5 in linear horizontal polarization mode for 7.0-GeV beam energy and 100-mA beam current. The minimum reachable harmonic energies were calculated assuming SmCo magnets and a $5.0 \mathrm{~mm}$ beam stayclear gap. The initial design values for the superconducting undulator (SCU) at $9.0 \mathrm{~mm}$ pole gap have been marked separately by the two Xs. The SCU at the first harmonic energy of $17.2 \mathrm{keV}$ nearly overlaps with the SmCo undulator at $5.0 \mathrm{~mm}$ gap. Ideal magnetic fields were assumed. 


\section{Total Power and On-Axis Power Density}

The total power and on-axis power density for the three in-vacuum undulators with period lengths ranging from $1.6 \mathrm{~cm}$ to $2.5 \mathrm{~cm}$ are shown in Figs. 7 and 8, respectively. The powers plotted in the figures are slightly less than those listed in Tables $1-3$ because $N$-2 periods were used instead of the full number of periods $N$. The figures provide a quick overview of the dependence on the harmonic energies; however, for exact maximum values, the tables should be used.

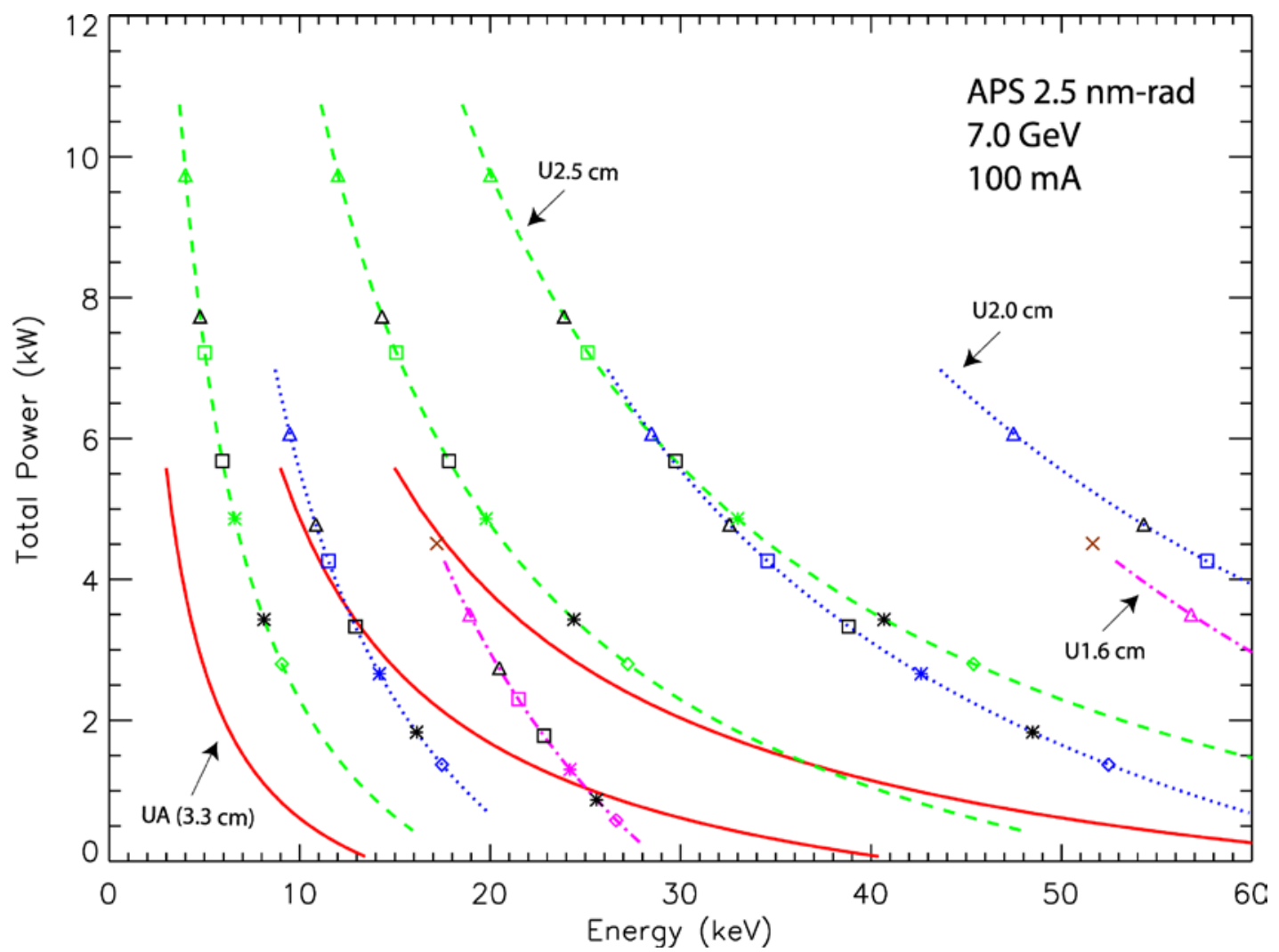

Fig. 7. Total power for three in-vacuum undulators $(1.6-\mathrm{cm}, 2.0-\mathrm{cm}$, and 2.5-cm period, each 2.4 $\mathrm{m}$ long) compared to undulator A for harmonics 1, 3, and 5 for $7.0-\mathrm{GeV}$ beam energy and 100$\mathrm{mA}$ beam current. Markers and notations are the same as in Fig. 6 . A reduced number of periods $(N-2)$ was used here. 


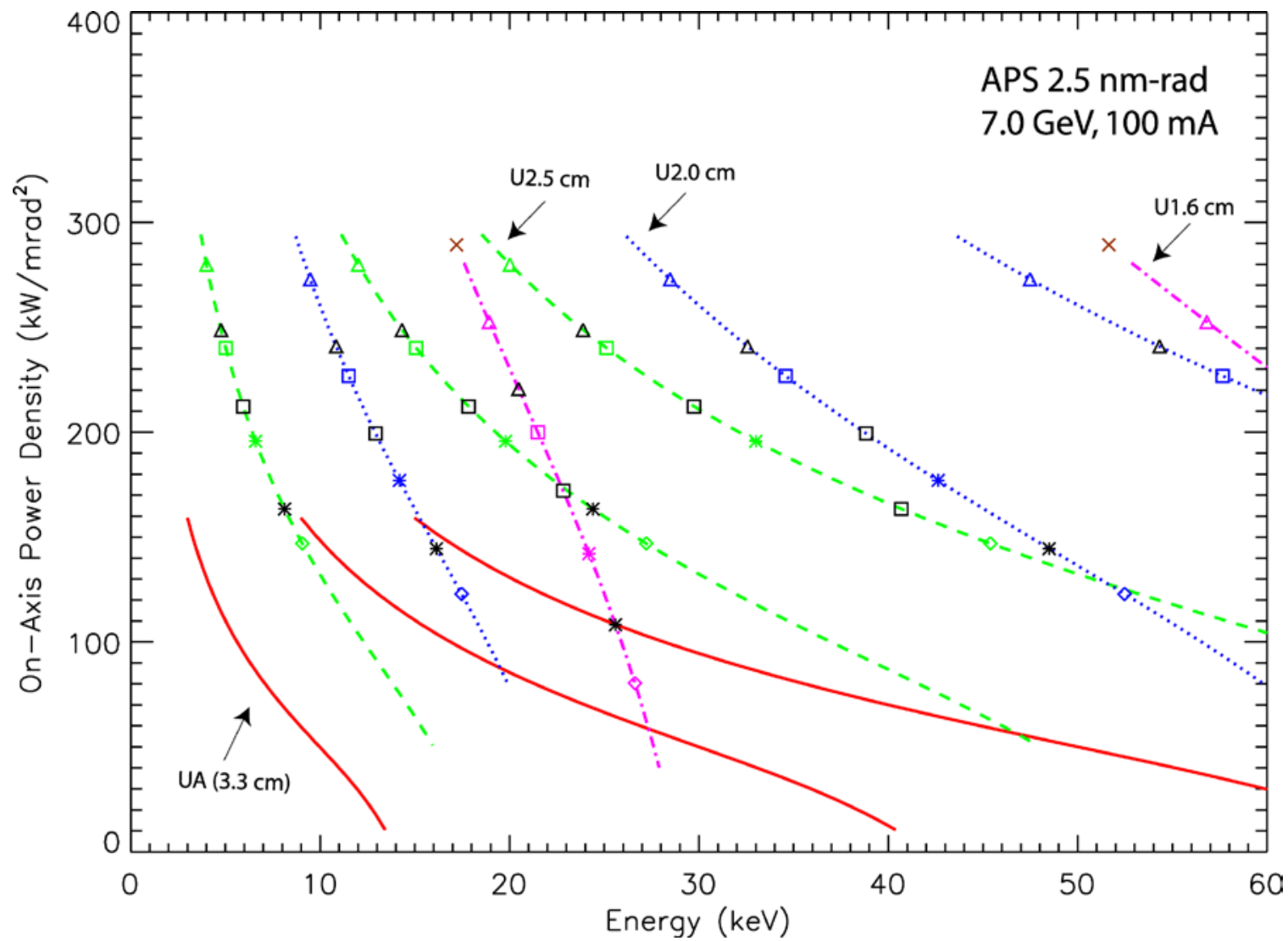

Fig. 8. On-axis power density for three in-vacuum undulators $(1.6-\mathrm{cm}, 2.0-\mathrm{cm}$, and $2.5-\mathrm{cm}$ period, each $2.4 \mathrm{~m}$ long) compared to undulator A for harmonics 1 , 3, and 5 for $7.0-\mathrm{GeV}$ beam energy and 100-mA beam current. Markers and notations are the same as in Fig. 6. A reduced number of periods $(N-2)$ was used here. 


\section{Comparison with Superconducting Undulators}

This section includes on-axis brilliance tuning curves and the total power and onaxis power density for nine planar superconducting undulators (SCUs) with period lengths ranging from $0.8 \mathrm{~cm}$ to $3.5 \mathrm{~cm}$ made of NbTi superconducting wires and 1010-steel poles and yokes. Undulators with period lengths larger than $2.5 \mathrm{~cm}$ would preferably be made of permanent magnets, because a sufficient tuning range may be achieved when installed on the standard vacuum chamber (minimum pole gap of 10.5 $\mathrm{mm}$ ) on the APS storage ring. The longer period lengths were included to show that the tuning range of the first harmonic may be extended to sub-keV photon energies. However, the maximum allowed total power of $21 \mathrm{~kW}$ for the newest APS beamlines would limit the lowest reachable first-harmonic energy for those period lengths. ${ }^{10}$ Undulator period lengths shorter than $1.4 \mathrm{~cm}$ are not viable options because of the limited tuning range due to the small magnetic field at a minimum pole gap of $7.0 \mathrm{~mm}$ (smallest beam-stay-clear gap assumed to be $5.0 \mathrm{~mm}$ ). They were included only for completeness and without regard to the design and manufacturing issues of very shortperiod superconducting undulators, which need to be resolved before they can be considered as viable options (at preferred small pole gaps of less than $7.0 \mathrm{~mm}$ ).

Several steps were involved to obtain the peak magnetic field $B_{0}$ in the undulator midplane for different undulator-gap-to-period ratios $(r)$. First, for a period of $1.6 \mathrm{~cm}$ and a magnetic pole gap of $8.0 \mathrm{~mm}(r=0.5)$, the code OPERA was used to calculate the maximum magnetic field in the coil $B_{\max }$ and the peak magnetic field $B_{0}$ in the undulator midplane for current densities in the coil $J$ ranging from 0.4 to $2.25 \mathrm{kA} / \mathrm{mm}^{2}$. The size of the undulator coil was $4.64 \mathrm{~mm} \times 4.64 \mathrm{~mm}$. The $J_{c}$ curve-i.e., the critical current density $J_{c}$ versus $B_{\max }$ - was calculated from the critical current versus field at $4.2 \mathrm{~K}$ provided by the vendor for a wire with a bare diameter of $0.70 \mathrm{~mm}(0.75 \mathrm{~mm}$ with insulation $)$ and a $\mathrm{Cu}$-to-superconductor ratio of 0.9 . The $J$ versus $B_{\max }$ value for the coil intersects with the $J_{c}$ curve, which determines the $J_{c}$ value, and $B_{0}$ was determined at that critical current density. Finally, the scaling law was used to calculate the $B_{\max }, J_{c}$, and $B_{0}$ values at other periods and pole gaps. ${ }^{11}$ The results of the calculations are shown in Fig. 9 and the data are listed in Tables $4-5$. Additional derived quantities related to radiation properties are listed in Table 6. 


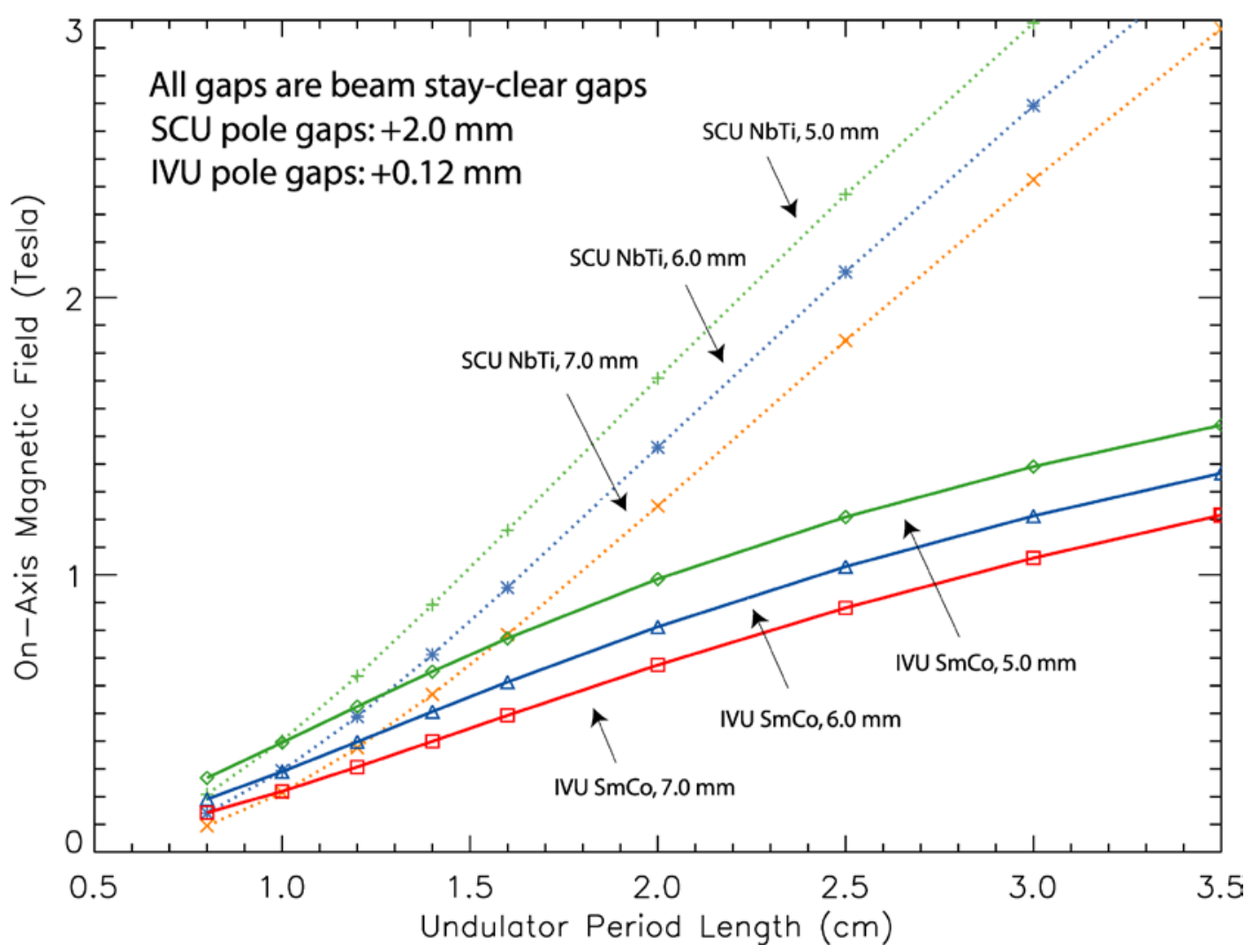

Fig. 9. Comparison of the magnetic field in the undulator midplane for in-vacuum SmCo undulators $\left(B_{e f f}\right)$ and NbTi superconducting undulators $\left(B_{0}\right)$ versus undulator period length for three beam stay-clear gaps. The actual undulator pole gaps were assumed to be $0.12 \mathrm{~mm}$ larger for the IVUs and $2.0 \mathrm{~mm}$ larger for the SCUs. Under these assumptions, about $2 \mathrm{~mm}$ is gained in the beam stay-clear gap for a 1.6-cm-period undulator. The effective field of the SCUs is approximately the same as the peak magnetic field $B_{0}$.

If the peak magnetic field $B_{0}\left(\sim B_{\text {eff }}\right)$ at a 9.0-mm gap for the 1.6-cm-period SCU is compared with the effective magnetic field of a SmCo in-vacuum undulator with the same period length, we notice that for the same beam-stay-clear dimension, the field of the SCU is 1.6 times stronger when a realistic thickness of the beam liner for the invacuum undulator $(2 \times 0.060 \mathrm{~mm})$ and a realistic wall thickness of the vacuum chamber for the SCU $(2 \times 1 \mathrm{~mm})$ are assumed. A beam-stay clear gap of $\sim 4.9 \mathrm{~mm}$ for the invacuum undulator would be necessary to reach the same field of 0.784 Tesla. This discussion is based on having the SCU operate at only $75 \%$ of the critical current $J_{c}$. 
Table 4: Calculated maximum magnetic field in the coil $B_{\max }$, critical current density in the coil $J_{c}$ for NbTi superconducting wires, and the peak magnetic field $B_{0}$ in the undulator midplane for different gap-to-period ratios $(r)$.

\begin{tabular}{|c|c|c|c|c|c|c|}
\hline $\begin{array}{l}\text { Undulator } \\
\text { Period } \\
(\mathrm{cm})^{\mathrm{a}}\end{array}$ & $B_{\max }(\mathrm{T})$ & $J_{c}\left(\mathrm{kA} / \mathrm{mm}^{2}\right)$ & $\begin{array}{c}B_{0}(\mathrm{~T}) @ J_{c} \\
(\mathrm{r}=0.5){ }^{\mathrm{b}}\end{array}$ & $\begin{array}{c}B_{0}(\mathrm{~T}) @ \\
0.75 J_{\mathrm{c}} \\
(\mathrm{r}=0.5)^{\mathrm{c}}\end{array}$ & $\begin{array}{c}B_{o}(\mathrm{~T}) @ \\
0.75 J_{c} \\
(\mathrm{~g}=9 \mathrm{~mm})\end{array}$ & $\begin{array}{c}B_{0}(\mathrm{~T}) @ \\
0.75 J_{c} \\
(\mathrm{~g}=10 \mathrm{~mm})\end{array}$ \\
\hline $0.8^{d}$ & 2.90 & 1.565 & 0.795 & 0.676 & 0.0948 & - \\
\hline 1.0 & 3.13 & 1.515 & 0.900 & 0.753 & 0.214 & - \\
\hline 1.2 & 3.34 & 1.468 & 0.994 & 0.825 & 0.376 & - \\
\hline 1.4 & 3.54 & 1.423 & 1.080 & 0.892 & 0.569 & - \\
\hline 1.6 & 3.73 & 1.381 & 1.161 & 0.954 & 0.784 & 0.644 \\
\hline 2.0 & 4.08 & 1.304 & 1.307 & 1.067 & 1.248 & 1.067 \\
\hline 2.5 & 4.47 & 1.218 & 1.463 & 1.189 & 1.845 & 1.627 \\
\hline 3.0 & 4.82 & 1.143 & 1.597 & 1.294 & 2.425 & 2.184 \\
\hline 3.5 & 5.12 & 1.076 & 1.713 & 1.385 & 2.970 & 2.715 \\
\hline
\end{tabular}

${ }^{\mathrm{a}}$ Results for a 1.6-cm period for a gap-to-period ratio $r=0.5$ was calculated with the code OPERA. Results for other periods and other $r$ ratios were obtained from the scaling law. Scaling law results for $B_{0}$ at 9.0- and 10.0-mm gaps for a 3.2-cm-period undulator (not shown) were verified with OPERA calculations and agreed to better than $0.5 \%$.

${ }^{\mathrm{b}}$ The difference between the peak magnetic field $B_{0}$ and the effective magnetic field $B_{\text {eff }}$ is less than $0.5 \%$ because of the near-sinusoidal shape of the magnetic field.

${ }^{\mathrm{C}}$ Operation at $0.75 J_{c}$ is assumed to provide a sufficient temperature stability margin to allow for beam heating and other safety factors for operation under cryogenic conditions. Operation at $0.75 J_{c}$ was arbitrarily chosen but is believed to be sufficient. Calculations assuming $0.8 J_{c}$ instead of $0.75 J_{c}$ would increase $B_{0}$ by about $4.5 \%$.

d The $J_{c}$ may be up to $11 \%$ higher for $B_{\max }$ smaller than $\sim 3.0 \mathrm{~T}$, and consequently $B_{0}$ becomes $\sim 7 \%$ larger.

Table 5: Calculated peak magnetic field $B_{0}$ for NbTi superconducting undulators and effective magnetic field $B_{\text {eff }}$ for in-vacuum SmCo undulators for different period lengths and pole gaps.

\begin{tabular}{ccccccc}
\hline $\begin{array}{c}\text { Undulator } \\
\begin{array}{c}\text { Period } \\
(\mathrm{cm}){ }^{\mathrm{a}}\end{array}\end{array}$ & $\begin{array}{c}\text { SCU } \\
\mathrm{g}=7.0 \mathrm{~mm} \\
\text { (Tesla) }\end{array}$ & $\begin{array}{c}\text { SCU } \\
\mathrm{g}=8.0 \mathrm{~mm} \\
\text { (Tesla) }\end{array}$ & $\begin{array}{c}\text { SCU } \\
\mathrm{g}=9.0 \mathrm{~mm} \\
\text { (Tesla) }\end{array}$ & $\begin{array}{c}\text { IVU } \\
\mathrm{g}=5.12 \mathrm{~mm} \\
(\text { Tesla })\end{array}$ & $\begin{array}{c}\text { IVU } \\
\mathrm{g}=6.12 \mathrm{~mm} \\
\text { (Tesla) }\end{array}$ & $\begin{array}{c}\text { IVU } \\
\mathrm{g}=7.12 \mathrm{~mm} \\
\text { (Tesla) }\end{array}$ \\
\hline & & & & & & \\
0.8 & 0.2080 & 0.1405 & 0.0948 & 0.2679 & 0.1913 & 0.1425 \\
1.0 & 0.4018 & 0.2935 & 0.2143 & 0.3954 & 0.2906 & 0.2195 \\
1.2 & 0.6349 & 0.4887 & 0.3761 & 0.5255 & 0.3979 & 0.3071 \\
1.4 & 0.8918 & 0.7125 & 0.5693 & 0.6518 & 0.5069 & 0.3998 \\
1.6 & 1.1609 & 0.9540 & 0.7839 & 0.7713 & 0.6137 & 0.4935 \\
2.0 & 1.7088 & 1.4604 & 1.2481 & 0.9856 & 0.8130 & 0.6752 \\
2.5 & 2.3724 & 2.0922 & 1.8452 & 1.2089 & 1.0300 & 0.8814 \\
3.0 & 2.9896 & 2.6924 & 2.4247 & 1.3907 & 1.2128 & 1.0609 \\
3.5 & 3.5536 & 3.2485 & 2.9696 & 1.5402 & 1.3668 & 1.2156 \\
& & & & & & \\
\hline
\end{tabular}

\footnotetext{
${ }^{\mathrm{a}}$ Results for an SCU with 1.6-cm period for a gap-to-period ratio $r=0.5$ was calculated with the code OPERA. Results for other periods and other $r$ ratios were obtained from the scaling law. The IVU results were obtained from the fit to computed values given in Table 1 and Fig. 2.
} 
It is interesting to note that the magnetic field $B_{0}$ for an SCU depends on the period length for any given gap-to-period ratio, see Table 4 for $r=0.5$. For permanent magnet undulators, with a fixed gap-to-period ratio, $B_{0}$ remains unchanged for different period lengths (see Magnet Modeling section, above). This can be explained by applying the scaling law. The scaling law states that if the undulator dimensions are scaled uniformly by a given period ratio and if Period $\times J=$ constant, then the distributions of the magnetic field and the permeability remain unchanged. The scaling law may easily be explained from Ampere's law only when magnetic materials are not involved. For example, if a SCU with a period of $1.6 \mathrm{~cm}$ is scaled up by a factor of two to $3.2 \mathrm{~cm}$ and other undulator dimensions are scaled by the same factor, then the 3.2-cm-period undulator will have the same magnetic field values at $J / 2$ as the 1.6-cm-period undulator at $J$. The $J_{c}$ for the 3.2-cm-period undulator is, however, higher than $J_{c} / 2$; hence, the $B_{0}$ becomes higher with increasing period lengths for a fixed value of $r$. 
Table 6: Calculated first harmonic energy, power density, and total power for nine superconducting undulators for a beam energy of $7.0 \mathrm{GeV}$ and a beam current of $100 \mathrm{~mA}$.

\begin{tabular}{|c|c|c|c|c|c|c|c|}
\hline $\begin{array}{l}\text { Undulator } \\
\text { Period }(\mathrm{cm})\end{array}$ & $\begin{array}{c}\text { Periods } \\
N^{\mathrm{a}} \\
\end{array}$ & $\begin{array}{c}\text { Pole Gap } \\
(\mathrm{mm})\end{array}$ & $\begin{array}{c}B_{0} \text { (Tesla) } \\
\text { (Calc.) }^{\text {b }}\end{array}$ & $K^{\mathrm{c}}$ & $\begin{array}{c}E_{1}{ }^{\mathrm{d}} \\
(\mathrm{keV})\end{array}$ & $\begin{array}{c}P_{\text {density }}{ }^{\mathrm{e}} \\
\left(\mathrm{kW} / \mathrm{mrad}^{2}\right)\end{array}$ & $\begin{array}{l}P_{\text {total }}{ }^{e} \\
(\mathrm{~kW}) \\
\end{array}$ \\
\hline 0.8 & 300 & $\begin{array}{l}7.0 \\
8.0 \\
9.0\end{array}$ & $\begin{array}{l}0.208 \\
0.141 \\
0.0948\end{array}$ & $\begin{array}{c}0.155 \\
0.105 \\
0.0708\end{array}$ & $\begin{array}{l}57.47 \\
57.84 \\
58.02\end{array}$ & $\begin{array}{l}55.10 \\
25.85 \\
11.94\end{array}$ & $\begin{array}{l}0.3 \\
0.1 \\
0.1\end{array}$ \\
\hline 1.0 & 240 & $\begin{array}{l}7.0 \\
8.0 \\
9.0\end{array}$ & $\begin{array}{l}0.402 \\
0.294 \\
0.214\end{array}$ & $\begin{array}{l}0.375 \\
0.275 \\
0.200\end{array}$ & $\begin{array}{l}43.47 \\
44.84 \\
45.62\end{array}$ & $\begin{array}{c}173.3 \\
102.3 \\
57.19\end{array}$ & $\begin{array}{l}1.2 \\
0.6 \\
0.3\end{array}$ \\
\hline 1.2 & 200 & $\begin{array}{l}7.0 \\
8.0 \\
9.0\end{array}$ & $\begin{array}{l}0.635 \\
0.489 \\
0.376\end{array}$ & $\begin{array}{l}0.712 \\
0.548 \\
0.421\end{array}$ & $\begin{array}{l}30.93 \\
33.71 \\
35.62\end{array}$ & $\begin{array}{l}298.6 \\
212.8 \\
144.6\end{array}$ & $\begin{array}{l}3.0 \\
1.8 \\
1.1\end{array}$ \\
\hline 1.4 & 171 & $\begin{array}{l}7.0 \\
8.0 \\
9.0\end{array}$ & $\begin{array}{l}0.892 \\
0.713 \\
0.569\end{array}$ & $\begin{array}{l}1.166 \\
0.932 \\
0.744\end{array}$ & $\begin{array}{l}19.79 \\
23.17 \\
26.03\end{array}$ & $\begin{array}{l}380.2 \\
298.5 \\
230.7\end{array}$ & $\begin{array}{l}5.9 \\
3.8 \\
2.4\end{array}$ \\
\hline 1.6 & 150 & $\begin{array}{r}9.0 \\
10.0\end{array}$ & $\begin{array}{l}0.784 \\
0.644\end{array}$ & $\begin{array}{l}1.171 \\
0.962\end{array}$ & $\begin{array}{l}17.25 \\
19.88\end{array}$ & $\begin{array}{l}293.2 \\
237.3\end{array}$ & $\begin{array}{l}4.6 \\
3.1\end{array}$ \\
\hline 2.0 & 120 & $\begin{array}{r}9.0 \\
10.0\end{array}$ & $\begin{array}{l}1.248 \\
1.067\end{array}$ & $\begin{array}{l}2.331 \\
1.993\end{array}$ & $\begin{array}{l}6.26 \\
7.79\end{array}$ & $\begin{array}{l}384.4 \\
327.1\end{array}$ & $\begin{array}{r}11.6 \\
8.5\end{array}$ \\
\hline 2.5 & 96 & $\begin{array}{r}9.0 \\
10.0\end{array}$ & $\begin{array}{l}1.845 \\
1.627\end{array}$ & $\begin{array}{l}4.307 \\
3.798\end{array}$ & $\begin{array}{l}1.81 \\
2.27\end{array}$ & $\begin{array}{l}459.2 \\
404.4\end{array}$ & $\begin{array}{l}25.3 \\
19.7\end{array}$ \\
\hline 3.0 & 80 & $\begin{array}{r}9.0 \\
10.0\end{array}$ & $\begin{array}{l}2.425 \\
2.184\end{array}$ & $\begin{array}{l}6.793 \\
6.118\end{array}$ & $\begin{array}{l}0.64 \\
0.79\end{array}$ & $\begin{array}{l}504.2 \\
453.9\end{array}$ & $\begin{array}{l}43.8 \\
35.5\end{array}$ \\
\hline 3.5 & 68 & $\begin{array}{r}9.0 \\
10.0\end{array}$ & $\begin{array}{l}2.970 \\
2.715\end{array}$ & $\begin{array}{l}9.706 \\
8.873\end{array}$ & $\begin{array}{l}0.28 \\
0.33\end{array}$ & $\begin{array}{l}525.3 \\
480.1\end{array}$ & $\begin{array}{l}65.1 \\
54.4\end{array}$ \\
\hline
\end{tabular}

\footnotetext{
${ }^{\mathrm{a}}$ All devices are $2.4 \mathrm{~m}$ long. The number of periods includes the non-full-strength end poles.

$\mathrm{b}$ The peak magnetic fields $B_{0}$ were taken from Table 5 .

${ }^{\mathrm{C}}$ The $K$ value was calculated from the relation: $K=0.934 \times B_{0}$ (Tesla) $\times$ Period $(\mathrm{cm})$. The difference between the peak magnetic field $B_{0}$ and the effective magnetic field $B_{\text {eff }}$ is less than $0.5 \%$, and since we have no information on the exact value of $B_{\text {eff }}$, the peak magnetic field was used. The $K$ value is too small for period lengths less than $1.4 \mathrm{~cm}$ to become viable options.

${ }^{\mathrm{d}}$ Zero-emittance calculation using the $K$ value for on-axis radiation for a beam energy of 7.0 GeV.

${ }^{\mathrm{e}}$ Zero-emittance calculation using the peak magnetic field $B_{0}$ for a beam energy of $7.0 \mathrm{GeV}$ and a beam current of $100 \mathrm{~mA}$. The maximum allowed on-axis power density is $590 \mathrm{~kW} / \mathrm{mrad}^{2}$, and total power is 21 $\mathrm{kW}$. If subject to the power load constraint of $21 \mathrm{~kW}$, the first harmonic energy would be limited to $\sim 0.8 \mathrm{keV}$ for the 3.5-cm-period SCU and $\sim 1.2 \mathrm{keV}$ for the 3.0-cm-period SCU. They may therefore be operated at a larger gap or lower current than that given in the table.
} 


\section{On-Axis Brilliance Tuning Curves for Superconducting Undulators}

The on-axis brilliance tuning curves for five superconducting undulators with period lengths from $1.6 \mathrm{~cm}$ to $3.5 \mathrm{~cm}$ are shown in Figs. $10-11$. Figure 10 shows the large overlap of the tuning curves for the longer period lengths, and Fig. 11 shows the same tuning curves with the overlaps removed. Clearly, the SCU $2.5 \mathrm{~cm}$ may operate at a 10.0-mm gap (actually higher than $10.0 \mathrm{~mm}$ ) and close the first- and third-harmonic tuning curves, or alternatively, the SCU $2.0-\mathrm{cm}$ may operate at $9.0-\mathrm{mm}$ gap and yet close the tuning curves.

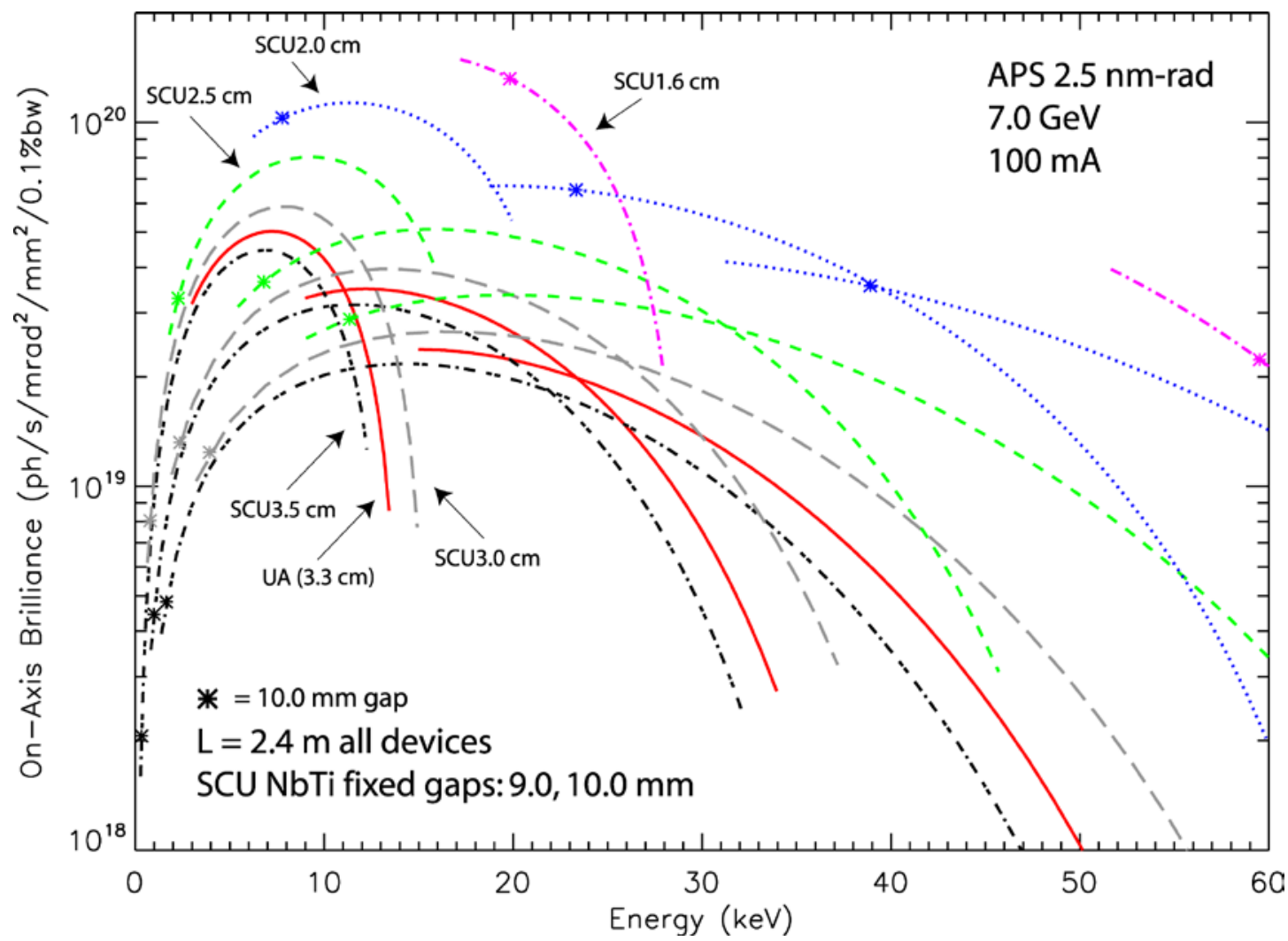

Fig. 10. On-axis brilliance tuning curves for five superconducting undulators $(1.6-\mathrm{cm}, 2.0-\mathrm{cm}$, 2.5-cm, 3.0-cm, and 3.5-cm periods, each $2.4 \mathrm{~m}$ long) compared to undulator A for harmonics 1 , 3 , and 5 in linear horizontal polarization mode for 7.0-GeV beam energy and 100-mA beam current. The minimum reachable harmonic energies were calculated assuming a $9.0 \mathrm{~mm}$ magnetic pole gap. The markers $(*)$ indicate the beginning of each harmonic tuning curve for a $10.0-\mathrm{mm}$ pole gap. Ideal magnetic fields were assumed. 


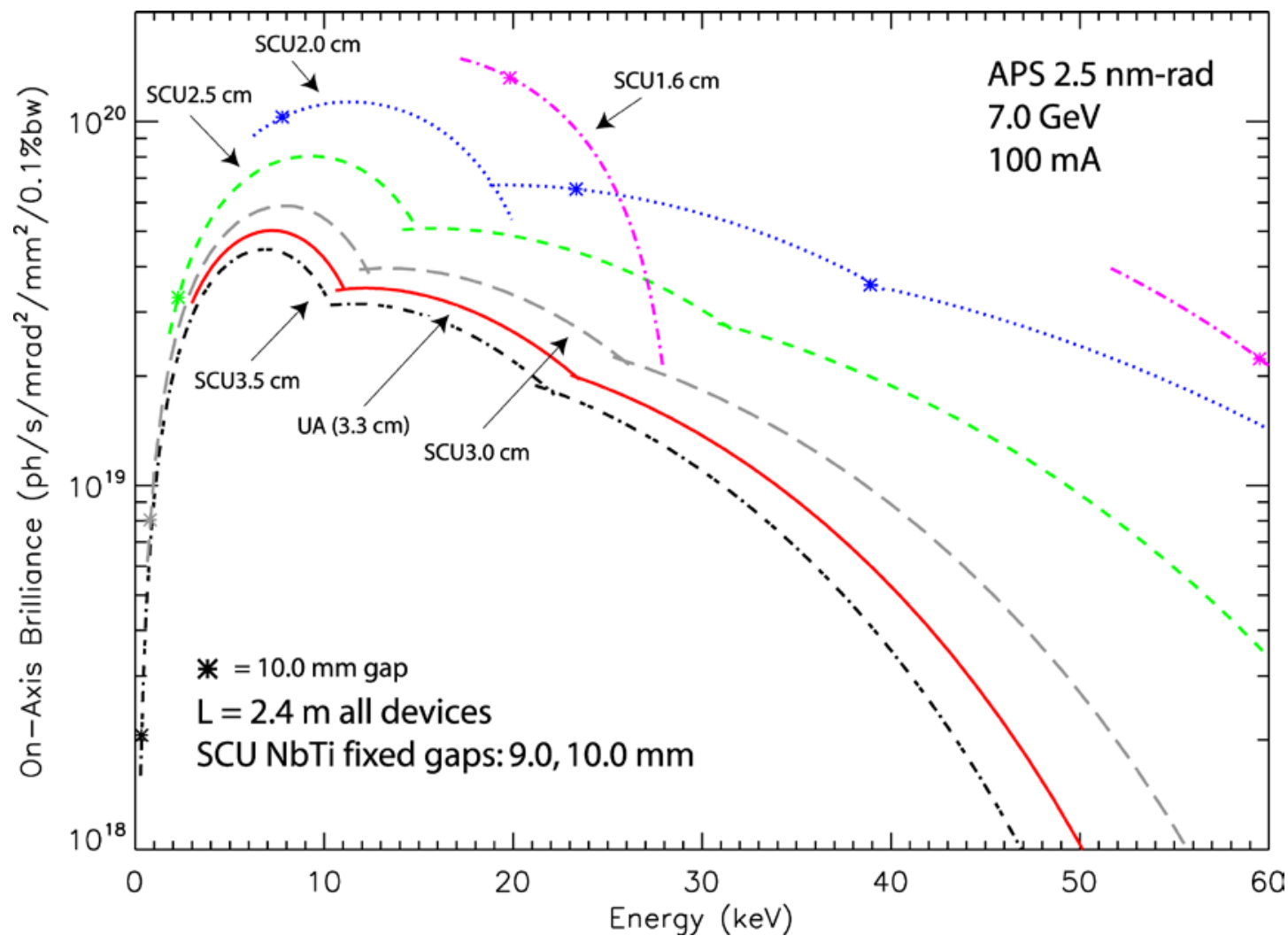

Fig. 11. On-axis brilliance tuning curves with the overlaps between harmonics removed for five superconducting undulators $(1.6-\mathrm{cm}, 2.0-\mathrm{cm}, 2.5-\mathrm{cm}, 3.0-\mathrm{cm}$, and $3.5-\mathrm{cm}$ periods, each $2.4 \mathrm{~m}$ long) compared to undulator A for harmonics 1, 3, and 5 in linear horizontal polarization mode for 7.0-GeV beam energy and 100-mA beam current. Other notations same as in Fig. 10. 


\section{Total Power and On-Axis Power Density for Superconducting Undulators}

The total power and on-axis power density for the five superconducting undulators are shown in Figs. 12 and 13, respectively. As before, the powers plotted in the figures are slightly less than those listed in Table 6 because $N-2$ periods were used instead of the full number of periods $N$.

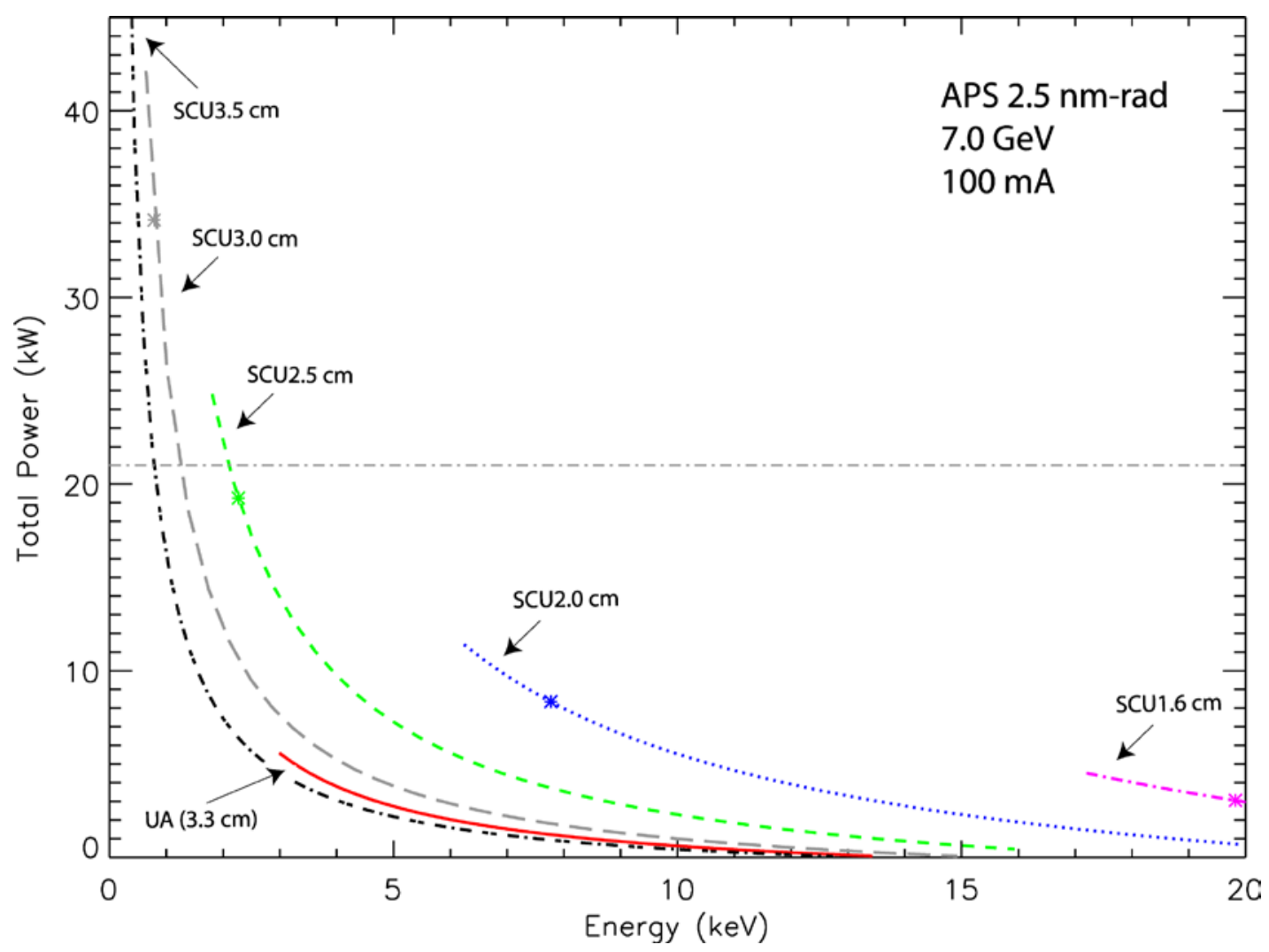

Fig. 12. Total power for five superconducting undulators $(1.6-\mathrm{cm}, 2.0-\mathrm{cm}, 2.5-\mathrm{cm}, 3.0-\mathrm{cm}$, and 3.5 -cm periods, each $2.4 \mathrm{~m}$ long) compared to undulator A for 7.0-GeV beam energy and 100$\mathrm{mA}$ beam current. The energy scale shows the first-harmonic energy tuning range. The dotteddashed horizontal line at $21 \mathrm{~kW}$ indicates the maximum power currently allowed for the APS beamlines. Markers and notations are the same as in Fig. 10. A reduced number of periods $(N-2)$ was used here. 


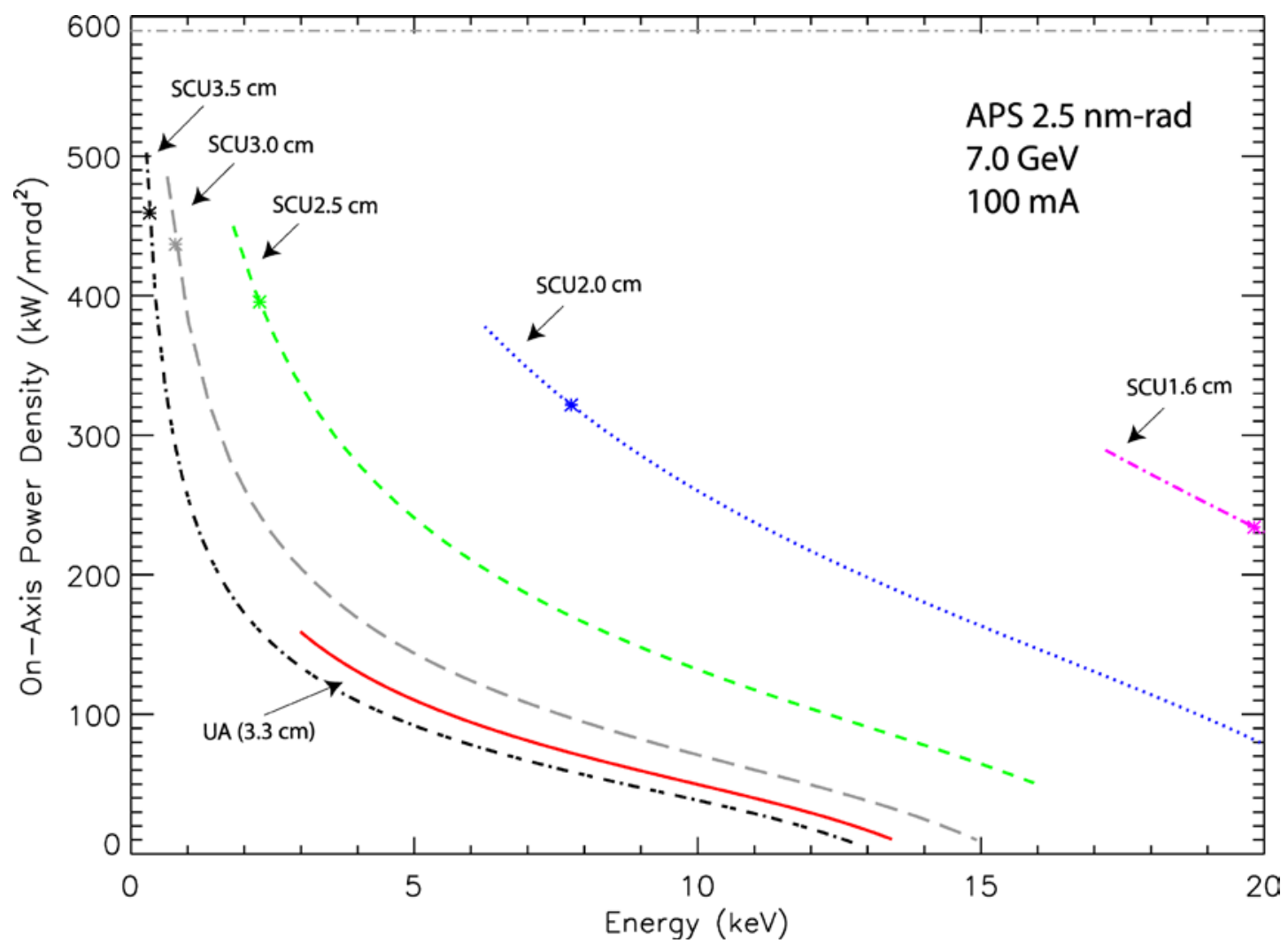

Fig. 13. On-axis power density for five superconducting undulators $(1.6-\mathrm{cm}, 2.0-\mathrm{cm}, 2.5-\mathrm{cm}, 3.0-$ $\mathrm{cm}$, and 3.5-cm periods, each $2.4 \mathrm{~m}$ long) compared to undulator A for 7.0-GeV beam energy and $100-\mathrm{mA}$ beam current. The energy scale shows the first-harmonic energy tuning range. The dotted-dashed horizontal line at $590 \mathrm{~kW} / \mathrm{mrad}^{2}$ indicates the maximum power density currently allowed for the APS beamlines. Markers and notations are the same as in Fig. 10. A reduced number of periods $(\mathrm{N}-2)$ was used here. 


\section{Discussion}

A comprehensive study of the expected performance of in-vacuum undulators installed on the APS storage ring was completed.

- From the 2D magnet optimization modeling of planar hybrid undulators, we calculated fitted parameters to computed data of the effective magnetic field $B_{\text {eff. }}$.

o For SmCo magnet undulator designs (grade R32HS from Shin-Etsu), we obtained

$$
B_{\text {eff }, \text { fit }}=2.940 \times \exp \left(-4.62 r+1.37 r^{2}\right) \text {, and }
$$

o for NdFeB magnet undulator designs (grade N39UH from Shin-Etsu), we obtained

$$
B_{\text {eff }, \text { fit }}=3.276 \times \exp \left(-4.51 r+1.20 r^{2}\right) \text {, where } r=\text { gap/period } \text {. }
$$

- 3D magnet optimization is expected to give slightly lower $B_{\text {eff }}$ (from a prior design of a $2.7-\mathrm{cm}$-period undulator at a $10.5-\mathrm{mm}$ gap, where we found $0.72 \%$ lower field for a 3D design). More recent 3D work of a 3.6-cm-period length undulator indicates that the reduction typically lies in the range $1-2 \%$. The reduction depends on many chosen design parameters, e.g., both the actual permanent magnet heights and widths and the pole heights and widths. Overall, it is fair to estimate that the reduction will be less than $2 \%$ due to $3 \mathrm{D}$ effects.

- Comparison of magnet design modeling with measured magnetic fields is somewhat difficult to do for several reasons:

o Magnet grades used in real undulators differ as does the remanence field $B_{r}$ of the actual batch of magnets delivered for a particular undulator. The $B_{r}$ values used in the model calculations are the minimum vendorspecified values, and the $B_{r}$ of the delivered magnets may be $1-2 \%$ higher.

0 The choice of the height of the permanent magnets and/or poles affects the $B_{\text {eff }}$ by $\sim 1 \%$.

0 There is pole gap uncertainty in the magnetic measurements. The gap is accurate to $\pm 100 \mu \mathrm{m}$, which translates into an error of $\Delta \mathrm{B} / \mathrm{B} \sim 1.0 \times 10^{-4}$ $\left(\mu \mathrm{m}^{-1}\right) \times \Delta$ gap $(\mu \mathrm{m}) \sim \pm 1 \%$. (The reference poles may differ by this fairly large amount from the average pole gap of the undulator.)

o Overall, we should not expect the agreement to be better than $\pm 2 \%$.

- The NbTi superconducting undulators outperform the SmCo in-vacuum undulators by a large margin. "Converted" to $\mathrm{mm}$, it is approximately $4 \mathrm{~mm}$ in the pole gap and $2 \mathrm{~mm}$ in the beam stay-clear gap for the proposed 1.6-cm-period SCU undulator for the APS. This translates into a stronger magnetic field by a factor of 1.6 of the SCU. The assumed thickness of the beam-liner of $0.12 \mathrm{~mm}$ for the IVUs may be somewhat underestimated, hence the real difference may be even larger. (The vacuum chamber wall thickness/space of $2.0 \mathrm{~mm}$ assumed for 
the SCU appears feasible.) Additionally, future work with $\mathrm{Nb}_{3} \mathrm{Sn}$ superconductors would provide even higher magnetic fields, thus supporting the ongoing superconducting undulator efforts. ${ }^{12}$

- The superconducting NbTi undulator with 2.0-cm period at 9.0-mm pole gap (beam stay-clear gap of $7.0 \mathrm{~mm}$ ) appears to be an attractive choice for continuous tuning range coverage.

0 A longer period length of $2.5 \mathrm{~cm}$ and a 6.0 -mm beam stay-clear gap are necessary for the in-vacuum SmCo undulators to similarly close the tuning curves.

o Alternatively, a SCU with a 2.5-cm period could be used and could operate at a much larger pole gap (larger than $10.0 \mathrm{~mm}$ ) to close the tuning curves.

- There are no power and power density issues identified, except for the very long period SCUs (periods longer than $2.5 \mathrm{~cm}$ ), which would not be viable options. 


\section{References}

${ }^{1}$ J. Chavanne et al., "In-Vacuum Undulators at the ESRF," Proceedings of the 2003 Particle Accelerator Conference (2003), pp. $253-255$.

${ }^{2}$ T. Tanaka et al., "In-Vacuum Undulators," Proceedings of the 27th International Free Electron Conference, (2005), pp. 370 - 377.

${ }^{3}$ S.H. Kim et al., "Development of Short-Period $\mathrm{Nb}_{3} \mathrm{Sn}$ Superconducting Undulators for the APS," IEEE Trans. Appl. Supercond. 18(2), (2008) 431 - 434.

${ }^{4}$ Y. Ivanyushenkov et al., "Status of R\&D on a Superconducting Undulator for the APS," Proceedings of the 2009 Particle Accelerator Conference, to be published at http://www.JACoW.org.

${ }^{5}$ J. Chavanne et al., "Recent Developments of Insertion Devices at the ESRF," Proceedings of the 1999 Particle Accelerator Conference (1999), pp. 2662 - 2664.

${ }^{6}$ Computer code OPERA from Cobham Technical Services; http://www.cobham.com/technicalservices

${ }^{7}$ Y.-C. Chae, private communication.

${ }^{8}$ Y.-C. Chae, "How many IVUs can we install without sacrificing 16-mA operation?,” APS Light Source Note ANL/APS/LS-318, April 2, 2009.

${ }^{9}$ G.K. Shenoy, P.J. Viccaro, and D.M. Mills, "Characteristics of the 7-GeV Advanced Photon Source: A Guide for Users,” Argonne National Laboratory Report, ANL-88-9, February 1988, Eq. 6, p. 18.

${ }^{10}$ Y. Jaski, private communication.

${ }^{11}$ S.H. Kim, "A scaling law for the magnetic fields of superconducting undulators," Nucl. Instrum. Methods A 546 (2005) $604-619$.

${ }^{12}$ S.H. Kim, private communication. 